\title{
Role of metabolite transporters in source-sink carbon allocation
}

\author{
Frank Ludewig* and Ulf-Ingo Flügge \\ Botanical Institute II, Cologne Biocenter, University of Cologne, Cologne, Germany
}

Edited by:

Yong-Ling Ruan, The University of Newcastle, Australia

\section{Reviewed by:}

Xinguang Zhu, Chinese Academy of

Sciences, China

Bob Creelman, Mendel

Biotechnology, Inc., USA

\section{${ }^{*}$ Correspondence:}

Frank Ludewig, Botanical Institute II, Cologne Biocenter, University of Cologne, Zülpicher Str. 47b,

50674 Cologne, Germany

e-mail: frank.ludewig@uni-koeln.de
Plants assimilate carbon dioxide during photosynthesis in chloroplasts. Assimilated carbon is subsequently allocated throughout the plant. Generally, two types of organs can be distinguished, mature green source leaves as net photoassimilate exporters, and net importers, the sinks, e.g., roots, flowers, small leaves, and storage organs like tubers. Within these organs, different tissue types developed according to their respective function, and cells of either tissue type are highly compartmentalized. Photoassimilates are allocated to distinct compartments of these tissues in all organs, requiring a set of metabolite transporters mediating this intercompartmental transfer. The general route of photoassimilates can be briefly described as follows. Upon fixation of carbon dioxide in chloroplasts of mesophyll cells, triose phosphates either enter the cytosol for mainly sucrose formation or remain in the stroma to form transiently stored starch which is degraded during the night and enters the cytosol as maltose or glucose to be further metabolized to sucrose. In both cases, sucrose enters the phloem for long distance transport or is transiently stored in the vacuole, or can be degraded to hexoses which also can be stored in the vacuole. In the majority of plant species, sucrose is actively loaded into the phloem via the apoplast. Following long distance transport, it is released into sink organs, where it enters cells as source of carbon and energy. In storage organs, sucrose can be stored, or carbon derived from sucrose can be stored as starch in plastids, or as oil in oil bodies, or - in combination with nitrogen - as protein in protein storage vacuoles and protein bodies. Here, we focus on transport proteins known for either of these steps, and discuss the implications for yield increase in plants upon genetic engineering of respective transporters.

Keywords: source-sink, carbon allocation, metabolite transporters, yield, storage

\section{LIMITATIONS FOR PLANT YIELD AND GENERAL CONSIDERATIONS}

Humans often exploit plant organs that serve plants for their persistence. Organs such as seeds, roots, tubers, or fruits contain considerable energy stored as oil, protein, sugar, or starch that allow the plant to start a new life cycle or its offspring to germinate. Seeds frequently are accompanied by or are embedded in fruits which also contribute to reproduction in that animals eat and often spread these fruits. Humans use these nutritious organs as food or feed and thousands of years ago had already started to propagate plants with better qualities by selective breeding. After long phases of selection-, classical and recently SMART (Selection with Markers and Advanced Reproductive Technologies; McCouch, 2004) breeding, the limits of quality or yield enhancement might be almost reached for some crops. In addition to these breeding programs, transgenic plants have been successfully engineered that often outcompete classically bred cultivars, e.g., plants with enhanced resistances against pathogens or herbicides. Although sometimes unacknowledged, especially by the European society, future prospects for transgenic plants being a farmer's first choice are intact. It can be assumed that new generations of transgenic plants also include those which are genetically engineered in their source- and/or sink capacity. These features are closely linked to the harvest index, i.e., weight of the grain (or other harvestable organs) divided by the total plant weight. Indeed, genetically engineered crop plants with changes in sourceand/or sink capacities were created which were either impaired (e.g., Riesmeier et al., 1994) or improved in yield (e.g., Jonik et al., 2012), demonstrating the feasibility and putative impact of such approaches on yield increase.

In general, the yield of a given cultivar is limited by several factors, and yield can only be improved by unrestricting these limitations. The challenge therefore is to know the limiting factor(s) of the respective crop.

This view, however, should be extended by referring to what is known about the cross-talk between source- and sink activities. When carbon reserves of storage organs are used up by the newly emerging seedling, photosynthesis begins and atmospheric $\mathrm{CO}_{2}$ is assimilated. Given an otherwise optimal supply with water, nitrogen, and other nutrients, only the rate of $\mathrm{CO}_{2}$ fixation determines plant growth during the vegetative phase. During further development toward maturation, storage organs are produced. The total of all sink organs then additionally determines the photosynthetic rate, as decreasing demand of the sink tissues for carbon ultimately 
limits photosynthesis, a phenomenon known as "sink limitation of photosynthesis" (Stitt, 1991; Paul and Foyer, 2001; Paul and Pellny, 2003; Ainsworth and Bush, 2011). Therefore, retention of the sink tissues to draw photosynthetic carbon would maintain photosynthesis (McCormick et al., 2006, 2008).

Here, we describe the allocation of carbon from source- to sink tissues and focus on the metabolite transporters known to be involved. We will also focus on C3 plants as the majority of these transporters have been described from these plant species.

\section{ALLOCATION OF CARBON WITHIN SOURCE LEAVES}

Production of carbon compounds occurs during photosynthesis in the chloroplasts. When the assimilated carbon exceeds the local need, carbon can then be exported. Net photoassimilate exporting leaves are defined as "source" (Turgeon, 1989). However, assimilated carbon can either be transiently stored as starch in chloroplasts or transported to the cytosol. From there, it can be directly exported from the leaf or transported into and transiently stored in the vacuole. From both compartments, chloroplasts and the vacuole, carbon can be exported when sink demand exceeds the actual production via photosynthesis, e.g., and of course during the diurnal cycle (starch release from the chloroplast at night). Transient storage of assimilated carbon in source leaves during the day could be regarded as a valve for excess carbon production and might be important for maintaining a high photosynthesis rate. At the same time, plants need this transiently stored carbon pool during the night to maintain sucrose formation for metabolic processes.

\section{CHLOROPLAST TRANSPORTERS}

During photosynthesis $\mathrm{CO}_{2}$ is assimilated in a series of reactions known as the Calvin-Benson cycle. One of six triose phosphates produced can either be used for starch production or can be exported from chloroplasts to the cytosol for sucrose synthesis or respiration. This export is accomplished by the triose phosphate/phosphate translocator (TPT; "1" in Figure 1; Fliege et al., 1978; Flügge et al., 1989) which exports triose phosphates in counter-exchange with orthophosphate (day path of carbon). Knock-out and -down tpt mutants and transgenic plants produce high amounts of starch during the day which are then partially degraded again during the day (Arabidopsis, tobacco; Häusler et al., 1998, 2000; Schneider et al., 2002; Walters et al., 2004; Schmitz et al., 2012) or the following night period (potato; Riesmeier et al., 1993a; Heineke et al., 1994). By this, tpt mutants and antisense plants manage to grow normally without any aberrant phenotype. Overexpression of the TPT was performed in tobacco using the Flaveria trinervia TPT gene (Häusler et al., 2000) and in Arabidopsis using the endogenous gene (Cho et al., 2012) with only minor effects. When a cytosolic fructose 1,6-bisphosphatase (cFBPase) was simultaneously overexpressed, Arabidopsis plants were larger

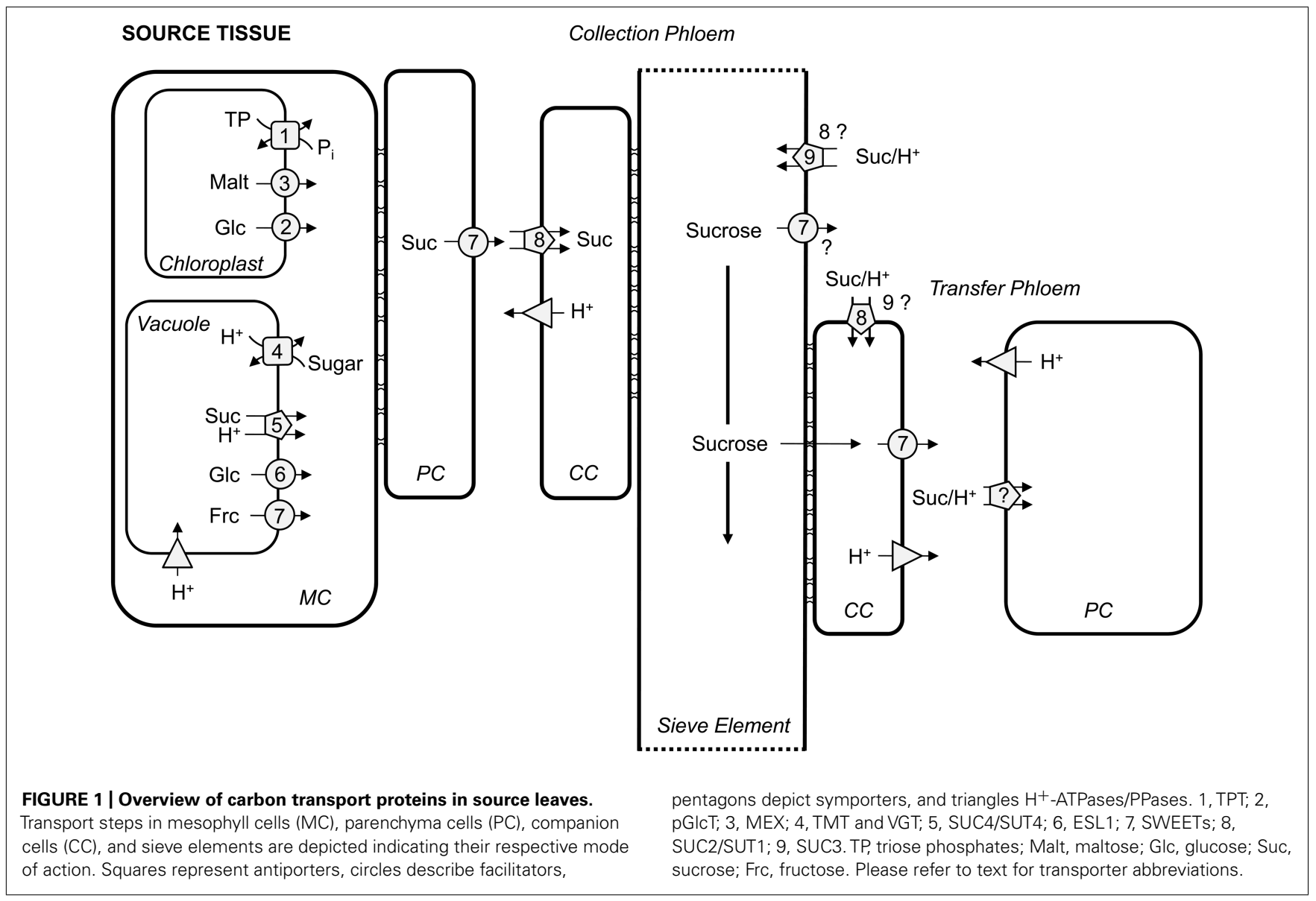


and exhibited a higher photosynthetic capacity (Cho et al., 2012). Unfortunately, no information on seed yield was provided. Thus, from this approach it cannot be deduced whether Arabidopsis yield could possibly be source-limited.

During the night, carbon export from the chloroplast starts with the breakdown of transitory starch and then export of the resulting products maltose and glucose. Weise et al. (2004) found evidence for maltose as the main product exported from chloroplasts at night and proposed a maltose transporter in addition to the plastid glucose transporter (pGlcT; " 2 " in Figure 1; Weber et al., 2000). Export of maltose is mediated by the maltose transporter MEX1 (“3” in Figure 1; Niittylä et al., 2004). The loss-of-function "maltose excess" mutant mexl was impaired in growth, had a light green yellowish appearance and accumulated maltose and starch. Overexpression of the endogenous transporter (Niittylä et al., 2004) as well as the apple (Malus domestica) transporter (Reidel et al., 2008) complemented the mutant phenotype. None of the lines that rescued the mexl phenotype displayed any additional aberrant phenotype indicating that MEX1 overexpression would not lead to increased growth or increased source capacity. Double mex1/tpt-2 or mex1/pglct but not pglct/tpt-2 mutants displayed an even more severe growth phenotype than mex1 (Cho et al., 2011) as well as a combination of starch synthesis $(a d g 1-1)$ or degradation (starch-excess 1-3, sex1-3) mutants with tpt mutants (Schneider et al., 2002). The severity of the respective phenotypes differed and the underlying reason is not yet fully understood, however, this might include retrograde signals from the chloroplasts to the nucleus (Stettler et al., 2009; Schmitz et al., 2012).

\section{VACUOLAR TRANSPORTERS}

In source leaves, sugar can be temporarily stored in vacuoles, e.g., when sucrose export via the phloem is saturated (Martinoia et al., 2000). The designation of sugar storage as "temporary" implies the existence of vacuolar sugar importers and exporters. The types of putative sugar importers known to date have been characterized from Arabidopsis thaliana, tonoplast monosaccharide transporters (TMTs; "4" in Figure 1; Wormit et al., 2006) and vacuolar glucose transporters (VGTs; “4” in Figure 1; Aluri and Büttner, 2007). Both types of transporters belong to the monosaccharide transporter (like) gene family, form a sub-clade each (Büttner, 2007, 2010) and mediate an energy-dependent transport driven by $\mathrm{V}$-type $\mathrm{H}^{+}$-ATPases and vacuolar $\mathrm{H}^{+}$-PPases. The transport direction by patch clamp technique has been shown to be sugar import into vacuoles for the TMTs (Wingenter et al., 2010; Schulz et al., 2011), while the function of VGT1 in seed germination and flowering as revealed by analyzing vgtl mutant plants also indicated glucose import into vacuoles (Aluri and Büttner, 2007). TMTs have been shown to import sugar in a proton antiport manner (Wingenter et al., 2010; Schulz et al., 2011), and putative VGT1-mediated glucose import is likely to be also coupled to proton antiport (Aluri and Büttner, 2007). Whereas initially and in accordance with their name TMTs were thought to transport monosaccharides across the tonoplast membrane (Wormit et al., 2006; Wingenter et al., 2010) recently it has been shown that also sucrose is transported by TMTs (Schulz et al., 2011). The Arabidopsis genome contains three TMT genes indicating possible redundancy for TMT function. Indeed, when analyzing loss-of-function tmt mutants, only tmt1/tmt2/tmt3 triple or tmt1/tmt2 double knock-out mutants showed impaired uptake of glucose into isolated mesophyll vacuoles (Wormit et al., 2006) or reduced sugar-induced changes in currents in patch clamp analyses (Wingenter et al., 2010), respectively. Double mutants grew worse, compared to wild-type, and were also impaired in seed yield, whereas double mutants additionally overexpressing the Arabidopsis TMT1 under the control of the 35S-CaMV promoter "over"-rescued the mutant phenotype due to higher TMT activity. This led to larger plants with increased seed yield. It was hypothesized that sugar sensing is diminished in overexpressing lines due to an increased import of sugars into the vacuole and - more importantly - out of the cytosol. These findings might indicate Arabidopsis "yield" to be source-limited (Wingenter et al., 2010). A sink effect, however, cannot be ruled out when using a constitutive promoter for the overexpression of TMT1. One could also imagine a sink effect, in that, sugar is transiently stored in vacuoles of embryo cells to perpetuate sucrose flow to sinks and thus increase sink strength.

Sugar export from the vacuole, on the contrary, is likely to occur in a proton symport manner or, when subcellular concentrations of the sugar to be transported allow for it, can occur by facilitated diffusion. To avoid a futile cycling of sugars into and out of the vacuole and thereby diminishing the proton gradient across the tonoplast, at least one of these processes should be regulated. Indeed, there is evidence for post-translational regulation of TMTs by phosphorylation. A member of the mitogen-activated protein 3-kinase called VH1-interacting kinase (VIK) was found to activate TMTs (Wingenter et al., 2011).

Sucrose transporters of type IV (SUC4/SUT4; “5” in Figure 1; Sauer, 2007; Kühn and Grof, 2010; Payyavula et al., 2011) of several species have been found to localize to the vacuolar membrane (Endler et al., 2006; Reinders et al., 2008; Eom et al., 2011; Payyavula etal., 2011; Schneider et al., 2012). The same clade has been designated "type III" by Reinders et al. (2012). Some of these sucrose transporters have been reported to localize to the plasma membrane (Weise et al., 2000; Weschke et al., 2000; Chincinska etal., 2008; Kühn and Grof, 2010). Although still under debate, we only discuss the function of this group of sucrose transporters as vacuolar transporters here. Schulz et al. (2011) were able to measure sucrose-driven proton import into the vacuole under an inverted $\mathrm{pH}$ gradient when overexpressing a functional AtSUC4-GFP (green fluorescent protein) construct in the background of the quadruple $t m t 1 /$ tmt $2 / v g t 1 / v g t 2$ mutant to overcome sugar/ $\mathrm{H}^{+}$-antiport activities - using the patch clamp technique. This result can only be interpreted as sucrose $/ \mathrm{H}^{+}$coexport from vacuoles mediated by SUC4 in vivo. An Arabidopsis suc4 loss-of-function mutant did not display any aberrant phenotype whereas constitutive SUC4 overexpressed seedlings had slightly less sucrose than wild-type (Schneider et al., 2012). The possible impact of SUC4 under- or overexpressing plants on seed yield was not reported by the authors. In contrast, sut 2 mutants of rice (OsSUT2 belonging to clade IV) had a reduced sugar export ability and accumulated sugars in source leaves which led to several aberrant phenotypes, among them growth retardation, reduction in tiller number and decreased grain weight (Eom et al., 2011). These findings are in line with the interpretation that SUT2mediated export of sucrose from vacuoles is important to sustain 
source capacity in rice. It remains to be elucidated whether or not the overexpression of SUT2 in rice leads to increased grain yield.

Evidence for a tonoplast hexose exporter has been gathered by Yamada et al. (2010). The authors mistargeted a slightly mutagenized Arabidopsis ESL1, a tonoplast-residing member of the ERD6-like monosaccharide transporters (“6” in Figure 1; Büttner, 2007, 2010), to the plasma membrane of tobacco BY-2 cells. Glucose transport across the membrane could be measured using ${ }^{14} \mathrm{C}$-glucose. Addition of high concentrations of unlabeled hexoses inhibited ${ }^{14} \mathrm{C}$-glucose transport to different extents depending on the sugar used for inhibition. The transport was found to be independent of a proton gradient, and determination of the $K_{\mathrm{m}}$ for glucose revealed ESL to be a low affinity facilitator exporting monosaccharides out of the vacuole (Yamada et al., 2010). ESL1 is expressed upon drought and salt stress, as are vacuolar invertases that produce hexoses from sucrose. ESL1-mediated export of hexoses from vacuoles might contribute to the plant's attempt to increase the osmotic potential within cells. The esl1 mutant, however, did not display any aberrant phenotype, perhaps due to redundancy (Yamada et al., 2010).

Another Arabidopsis ERD6-like monosaccharide transporter, ERDL6, has been described as vacuolar glucose exporter by Poschet et al. (2011). Expression of ERDL6 is induced when sugars are mobilized, e.g., in darkness, upon heat stress or wounding, and is reduced upon cold stress or external feeding of sugars to the plant. Elevated levels of glucose, but not of fructose and sucrose, were found in erdl6 mutants, and non-aqueous fractionation revealed a more pronounced glucose increase in vacuoles compared to extra-vacuolar compartments. The opposite effect of lower glucose contents, however, was described for overexpressors either of the endogenous or a homologous sugar beet transporter (BvIMP). Knock-out erdl6 mutants, however, displayed increased seed yield with elevated sugar, protein, and lipid contents of mature seeds, as had been described for TMT1 overexpressors (Wingenter et al., 2010). It remains elusive if yield increase can be attributed to source or sink effects since ERDL6 is expressed in leaves and seeds, according to the eFP browser (Winter et al., 2007). It also remains to be elucidated whether the mechanism of ERDL6-mediated transport is facilitation - as found for ESL1 - or is secondary transport.

Only very recently, the Arabidopsis vacuolar sugar exporter SWEET17 has been discovered with help of a quantitative genetics approach (“7” in Figure 1; Chardon et al., 2013). SWEET17 is the first protein among the SWEET transporter family localized to the tonoplast, all other SWEETs described previously were localized in the plasma membrane (Chen et al., 2010, 2012). Moreover, SWEET17 is the first fructose transporter, other SWEET family members facilitate diffusion of glucose or sucrose (Chen et al., 2010, 2012). The authors were able to demonstrate uptake or efflux of ${ }^{13} \mathrm{C}$-labeled fructose upon expression of SWEET17 in Xenopus oocytes. In sweet 17 mutants, fructose contents were enhanced compared to wild-type, and accumulation of fructose was more pronounced in nitrogen-limited or cold-stressed plants. Both growth conditions led to an elevated uptake of sugars into vacuoles mediated by TMTs (Wingenter et al., 2010; Schulz et al., 2011), and fructose appears to not be released from sweet17 mutant vacuoles. SWEET17 expression was found in leaves, with the strongest level in xylem vascular tissue, pointing toward a function in fructose allocation within the plant. Accordingly, the only subtle phenotype of sweet 17 mutants was in the reduced size of flower stalks and slightly reduced seed yield (Chardon et al., 2013).

\section{PHLOEM LOADING, LEAKAGE, AND RETRIEVAL}

When sucrose is exported from source leaves, it has to enter the phloem. Several strategies for the loading of sucrose (and other sugars and sugar alcohols) have been described (for a review, see Rennie and Turgeon, 2009). We have restricted ourselves here to apoplastic sucrose loading when describing the route sucrose takes from source leaves to sinks.

\section{SWEET-FACILITATED SUCROSE EFFLUX INTO THE APOPLAST}

For many years it remained unknown how sucrose is released from mesophyll cells or phloem parenchyma cells into the apoplast prior to loading into the companion cell/sieve element complex. It was recently demonstrated that this release is facilitated by members of the SWEET transporter family, i.e., SWEET11 and -12 from Arabidopsis and SWEET11 and -14 from rice ("7" in Figure 1; Chen etal., 2012). Facilitation of sucrose efflux without energy consumption can occur due to the concentration gradient between the mesophyll cell/phloem parenchyma cell symplastic continuum and the apoplast has been described to be steep [40-, 150-, and 750fold in spinach, barley (Lohaus et al., 1995), and sugar beet (Fondy and Geiger, 1977; Lohaus et al., 1994), respectively]. Closing of this gap in source sink carbon allocation was of great importance and accordingly was effusively acclaimed (Baker et al., 2012; Braun, 2012) not only because of the completion of a pathway but also due to enabling new perspectives with respect to genetic engineering of the SWEET proteins. Before sucrose transporting SWEETs had been discovered, other members of the family were found to facilitate efflux of glucose into the apoplast fulfilling a potential role in feeding pathogens residing in the cell wall (Chen et al., 2010) with maybe even higher potential for the agricultural industry (Sonnewald, 2011; Baker et al., 2012).

Whereas, single knock-out mutants of AtSWEET11 and 12 did not display any obvious altered phenotype, Arabidopsis sweet $11 /$ sweet 12 double mutants did display an expected phenotype of blocked phloem loading, i.e., smaller plants, elevated levels of leaf starch and sucrose, a reduced export of fixed ${ }^{14} \mathrm{C}$ from leaves and reduced growth of sinks (e.g., roots; Chen et al., 2012). Rice SWEET11 and -14 were transcriptionally induced upon infection with Xanthomonas oryzae pv. oryzae. This induction is mediated through pathogen-borne effectors binding to SWEET11 and -14 promoters. Mutations in the binding sites led to resistance against the pathogen (Antony et al., 2010). This finding indicated that increasing SWEET activity would lead to more sucrose in the apoplast on which pathogens could feed and spread. Thus, an overexpression of SWEETs in non-infected plants would most likely also lead to an increase in apoplastic sucrose content. Whether or not SWEET overexpression could enhance source capacity would depend on the plasticity of SUC2/SUT1 transporter (" 8 " in Figure 1) activity importing sucrose from the apoplast into phloem companion cells in a sufficient capacity. 


\section{PHLOEM LOADING OF SUCROSE}

Sucrose is loaded into phloem companion cells and is transported in sieve elements along a hydrostatic pressure gradient driven by active sucrose loading. This enables a mass flow to sink organs with higher pressure in the source leaves and lower pressure in the sinks where sucrose is then unloaded from the phloem (Münch, 1930).

Because of the extreme difference in sucrose concentration between apoplast and phloem, sucrose loading against this gradient [630-, 700-, and 15,000-fold in spinach, barley (Lohaus et al., 1995), and sugar beet (Fondy and Geiger, 1977; Lohaus et al., 1994), respectively] must be energized. Apoplastic sucrose loading proceeds via a sucrose $/ \mathrm{H}^{+}$-symport (Giaquinta, 1977a,b; Komor et al., 1977; Delrot and Bonnemain, 1981; Bush, 1989) using the proton gradient which is established by the plasma membranelocated P-type $\mathrm{H}^{+}$-ATPase. Direct evidence for an apoplastic step in sucrose loading into the phloem was provided by the expression of a yeast invertase in the apoplast (cell wall) of Arabidopsis, tobacco, tomato, and potato that led to increased carbohydrate levels in mature leaves and a concomitant decrease of photosynthesis (von Schaewen et al., 1990; Dickinson et al., 1991; Sonnewald et al., 1991; Heineke et al., 1992) resulting in reduced growth rates. These experiments demonstrated that only sucrose but not hexoses can be loaded into the phloem. The respective SUC2/SUT1 $\mathrm{H}^{+}$-cotransporters have been identified by functional complementation of yeast strains unable to grow on sucrose (Riesmeier et al., 1992, 1993b; Sauer and Stolz, 1994). Expression of these transporters was confined to the phloem (Riesmeier et al., 1993b; Gahrtz et al., 1994; Truernit and Sauer, 1995), and more precisely to companion cells (Stadler et al., 1995; Stadler and Sauer, 1996; Schmitt et al., 2008). Functional proof was established by antisense down-regulation of the SUT1 proteins from potato (Riesmeier et al., 1994; Kühn et al., 1996) and tobacco (Bürkle et al., 1998). Knock-out suc2 Arabidopsis (Gottwald et al., 2000) and sut1 maize (Slewinski et al., 2009, 2010) plants were characterized and displayed a similar phenotype to that found for the Solanaceae: carbohydrate accumulation in leaves, impaired growth and generally poor development of sinks. Over expression of a modified spinach SUT1 in potato did not lead to increased tuber starch content and yield (Leggewie et al., 2003). This could either be due to the use of a constitutive promoter to drive expression of the SUT1 gene in mesophyll and phloem parenchyma cells that might have led to an unwanted re-uptake of sucrose from the apoplast into these cells and thus partial prevention of phloem loading. On the other hand, SUT1 activity might not be limiting for sucrose delivery to sink tissues or that potato tuber yield is not source-limited. Arabidopsis suc2 mutants have been successfully complemented with the Arabidopsis SUC1 gene expressed under control of the AtSUC2 promoter. Some of these complemented lines displayed decreased leaf sucrose content indicative of more effective sucrose loading into the phloem (Wippel and Sauer, 2012). However, a possible impact on source capacity remains ambiguous since neither carbon export nor seed yield was comparatively analyzed in these plants. By over- and underexpressing the vacuolar TMT in Arabidopsis leaves, Wingenter et al. (2010) posed an indirect effect on SUC2 transcripts, sucrose export from leaves and seed yield which have been found to positively correlate with TMT activity.
However, it has to be elucidated whether or not TMT or other factors affect SUC2 activity which would in turn be accountable for altered source capacity.

\section{LEAKAGE FROM AND RETRIEVAL OF SUCROSE TRANSPORTED IN THE PHLOEM}

Sucrose in the phloem is transported to the sink tissues from the leaves and partially leaks out of the phloem to nourish the surrounding tissue (Minchin et al., 1984; Minchin and Thorpe, 1987). Whereas the above-ground tissues are green and might be able to support themselves to a certain extent by photosynthesis, the below-ground tissues clearly depend on sucrose leakage out of the phloem. How and where sucrose leaks out of the phloem has not been analyzed in detail. The sieve element/companion cell complex seems to be symplastically isolated (Kempers et al., 1998) along the whole path of sucrose movement indicating that unloading from the sieve elements and/or companion cells into the apoplast has to be facilitated. It remains to be elucidated whether SWEETs (" 7 " in Figure 1) are expressed in sieve elements or companion cells along the phloem and are responsible for this function.

Having entered the apoplast, sucrose then has to be taken up into the symplast again to reach the sink cells that depend on sucrose import. On the other hand, a great proportion of the sucrose that leaked out is retrieved into the sieve element/companion cell complex (Hafke et al., 2005). In both directions, uptake must be energized (Ayre, 2011), and thus sucrose $/ \mathrm{H}^{+}$-cotransporters are likely to fulfill this function. In Arabidopsis, the role of SUC2 ("8" in Figure 1) in retrieval of sucrose from the apoplast has been described by complementing the suc2 mutant with a construct that restored SUC2 function in phloem loading (see above) but not in retrieval. The corresponding plants were smaller and exuded less ${ }^{14} \mathrm{C}$ label from cut petioles when leaves photosynthesized in the presence of ${ }^{14} \mathrm{CO}_{2}$. These findings are consistent with a role of SUC2 in retrieval of sucrose from the apoplast along the phloem (Srivastava et al., 2008). Analyses using ${ }^{11} \mathrm{C}$ tracer studies support this role for AtSUC2 (Gould et al., 2012). In addition, localization in the sieve elements of Arabidopsis stems argues for a putative role of SUC3 in retrieval ("9" in Figure 1; Meyer et al., 2000, 2004). This is in addition to SUC2 which seems to retrieve sucrose back into companion cells. However, it remains unclear which sucrose $/ \mathrm{H}^{+}$-cotransporters function in taking up sucrose to nourish the tissue surrounding the vasculature.

\section{CARBON UNLOADING AND STORAGE IN SINK ORGANS}

Unloading of sucrose from the phloem can occur symplastically or apoplastically, depending not only on the plant species but also on tissue types and developmental stages.

\section{OIL STORAGE IN PLANTS}

Most of the research on plants that store oil in their seed was performed on Arabidopsis thaliana. The important seed oil crop canola with cultivars of rapeseed (Brassica napus) or field mustard (Brassica rapa) belongs to the same family as Arabidopsis, the Brassicaceae. However, other plants with oil-storing seeds belong to the Asteraceae family, e.g., sunflower (Helianthus annuus), to 
the Fabaceae family, e.g., soybean (Glycine max), or the Arecaceae family, e.g., oil palms (Elaeis guineensis, Elaeis oleifera, Attalea maripa). Oil palms not only store oil in their seeds but also in their fruits.

However, sucrose delivered from source leaves via the phloem has to reach the terminal storage sinks, i.e., seeds and/or fruits, thereby crossing several membranes. Once there, sucrose undergoes a series of metabolic reactions to be stored as triacylglycerol (TAG) in the embryo again including several transport steps of intermediates across membranes. We will focus on Arabidopsis to describe the path of carbon from sucrose to TAG in the following paragraphs.

To define the symplastic domains, mobile and immobile versions of the GFP under the control of a variety of promoters as well as the low-molecular-weight fluorescent dye HPTS (8hydroxypyrene-1,3,6-trisulfonate) were used (Schneidereit et al., 2003; Stadler et al., 2005a).

Having reached the funicular end of the phloem, sucrose is unloaded into an unloading domain near the funiculus, and post-phloem transport occurs symplastically into the seed coat (Imlau et al., 1999), or - more precisely - into the outer integument (Stadler et al., 2005b). Before anthesis, phloem unloading of sucrose switches from symplastic in ovule primordia cells to apoplastic in mature ovules and upon anthesis back to a symplastic mode (Werner et al., 2011). To progress into the inner integument, sucrose must reach the apoplast which is potentially facilitated by SWEETs. A sucrose $/ \mathrm{H}^{+}$-symporter could also potentially transport sucrose into the inner integument. SUC3 has been discussed as a likely candidate (Stadler et al., 2005b) since it might be expressed in this cell layer (Meyer et al., 2004). However, the transfer of sucrose from the outer into the inner integument has not been analyzed in detail. The three layers of the inner integument form a symplastic continuum (Stadler et al., 2005b) isolated from the endosperm. After export from the inner integument, possibly mediated by a SWEET transporter, sucrose could be taken up into the endosperm by SUC5 which is expressed during seed development (Baud et al., 2005; Stadler et al., 2005b; Pommerrenig et al., 2013). Finally, before entering the embryo, sucrose has to be released into the apoplast separating endosperm and embryo. Again, one can speculate of a SWEET transporter family member (" 7 " in Figure 2) facilitating diffusion of sucrose out of the endosperm. Sucrose uptake into the embryo could be managed by three different SUC proteins (SUC3, -5, -9; Figure 2) that are expressed in different embryonic tissues at different developmental stages. With the help of a SUC9 promoter-GUS fusion, SUC9 expression could be detected in the mature embryo (Sivitz et al., 2007). More detailed analyses have been performed for the expression of both SUC5 and SUC3. In addition to the expression of SUC5 in the endosperm, torpedo and walking stick stage embryos express SUC5 in the epidermis of cotyledons (Pommerrenig et al., 2013). SUC3 is expressed in the suspensor which forms a symplastic continuum with the globular embryo. However, as early as the heart stage, the embryo proper is again symplastically isolated from the suspensor (Stadler et al., 2005b). From the torpedo stage on, SUC3 is expressed in the root epidermis which forms a symplastic connection with root and hypocotyls cells (Meyer et al., 2004; Stadler et al., 2005b). In almost fully developed embryos, SUC3 is still expressed in the root epidermis but seems to form a symplast with cells of the developing stele. Moreover, individual symplastically isolated cells of cotyledons express SUC3 (Stadler et al., 2005b). However, there seems to be redundancy in the described steps since none of the individual mutants displayed a phenotype different from wild-type. Whereas, there was no aberrant suc3 phenotype detectable at all (Barth et al., 2003), suc5 mutants displayed a transient decrease in seed TAG accumulation (Baud et al., 2005) which might be explained by the biotin transport function of SUC5 rather than the sucrose transport function (Pommerrenig et al., 2013). Under short-day conditions, suc9 mutants show an early flowering phenotype but normally are indistinguishable from wild-type (Sivitz et al., 2007).

Once having reached the cytosol of embryo cells, sucrose is utilized to keep up metabolism and ultimately to build up TAG. TAG is formed from glycerol 3-phosphate (Gly3P) and acylated fatty acids in the endoplasmic reticulum (ER) in a series of reactions known as the Kennedy pathway (Kennedy, 1961). In plants, fatty acid synthesis takes place exclusively in plastids, and in heterotrophic tissues plastids depend on the import of carbon skeletons, energy and reduction power (Rawsthorne, 2002). Fatty acid synthesis starts from pyruvate that is first converted to acetyl-CoA by the plastidic pyruvate dehydrogenase complex. For synthesizing fatty acids from acetyl-CoA, ATP and $\mathrm{NAD}(\mathrm{P}) \mathrm{H}$ are required and thus have to be imported or generated within plastids. Carbon skeletons can be imported into plastids as glucose 6-phosphate (Glc6P), pyruvate, phosphoenolpyruvate (PEP), or malate. These metabolites are either intermediates of glycolysis, or in the case of malate, a tricarboxylic acid (TCA) cycle intermediate that can be exported from the mitochondria into the cytosol.

Glucose 6-phosphate is imported into plastids by the Glc6P/phosphate translocator (GPT; "10" in Figure 2; Kammerer et al., 1998) in counter-exchange with inorganic phosphate or triose phosphate generated by the oxidative pentose phosphate pathway (OPPP). Plastids isolated from young oilseed rape embryos utilize Glc6P better than pyruvate for fatty acid synthesis whereas plastids isolated from older embryos prefer pyruvate over Glc6P as a substrate for fatty acid synthesis (Eastmond and Rawsthorne, 2000). Moreover, imported Glc6P is also used for starch synthesis or as a substrate of the OPPP which is necessary for the production of NADPH required for fatty acid synthesis. Furthermore, partitioning of Glc6P into the different pathways is dependent on the developmental stage of the embryos (Eastmond and Rawsthorne, 2000). Seeds of Arabidopsis and oilseed rape transiently accumulate starch but completely degrade it until they reach maturity (da Silva et al., 1997; Baud et al., 2002; Andriotis et al., 2010a). Starch does not accumulate because of photosynthetic activity of the embryo and/or the seed coat, since seeds developing in darkened siliques also show transient starch accumulation (da Silva et al., 1997). It might be assumed that transient starch accumulation of seeds could be important for final TAG yield of embryos since Arabidopsis mutants defective in starch degradation (sexl; Yu et al., 2001) or biosynthesis (phosphoglucomutase 1, pgm1; Caspar et al., 1985) were found to contain 30 (Andriotis et al., 2010a) and 40\% (Periappuram et al., 2000) less lipid content, respectively. In oilseed rape, the embryo-specific reduction of ADP-glucose pyrophosphorylase (AGPase) activity, 
i.e., down-regulation of starch synthesis, led to a delay in oil accumulation of developing seeds. However, mature seeds had wild-type seed oil content (Vigeolas et al., 2004). Andriotis et al. (2012) were able to show that starch turnover of the maternal plant is important for Arabidopsis seed TAG yield, and not starch turnover of the embryo itself, i.e., they found a reduction in (mainly nocturnal) source capacity causative for compromised seed TAG content. Nonetheless, Glc6P uptake and partitioning into fatty acid and the OPPP seems to be of major importance since restricting GPT activity by seed-specific antisense expression or RNA interference (RNAi) led to an arrest of embryo development despite the redundancy of carbon skeleton uptake systems of plastids. As mentioned above, pyruvate as a direct substrate for fatty acid synthesis can also be taken up by plastids. The plastid sodium-dependent pyruvate transporter BASS2 was found to import pyruvate into plastids ("11" in Figure 2; Furumoto et al., 2011). Alternatively, pyruvate can be produced from PEP that could either be formed within the plastid stroma (Flügge et al., 2011) or imported by the PEP/phosphate translocator (PPT; "12" in Figure 2; Fischer et al., 1997). Moreover, malate can also serve as a precursor for stromal pyruvate. NADP malic enzyme produces pyruvate, $\mathrm{CO}_{2}$ and reduction power from malate that could be imported into plastids by the dicarboxylate transporter DiT2 (“13” in Figure 2; Renné et al., 2003). However, none of these substrates can fuel the OPPP. Therefore, compromised generation of sufficient reduction power might explain the severity of the GPT antisense or RNAi plant phenotype (Andriotis et al., 2010b). Whereas, in bass 2 mutants there was no aberrant phenotype under normal growth conditions, though these were not analyzed for fatty acid or seed TAG content (Furumoto et al., 2011), ppt1 (cue1; Li et al., 1995) mutants display a reticulate phenotype that spoils meaningful yield analyses. The supposed reason for the apparent phenotype is that PPT1 is not only involved in substrate supply for fatty acid synthesis but also important in secondary metabolite production (Streatfield et al., 1999; Voll et al., 2003).

DiT2 is essential for photorespiration, in that, dit2 (dct; Somerville and Ogren, 1983; Somerville and Somerville, 1985) mutants do not re-assimilate ammonium released during photorespiration due to a lack of glutamate export from plastids and do not survive when grown under ambient $\mathrm{CO}_{2}$ concentrations.

As mentioned above, energy has to be imported into heterotrophic plastids to drive - amongst other processes - transient starch synthesis and optimal fatty acid synthesis. Plastids import ATP via adenylate translocators (NTTs; "14" in Figure 2;

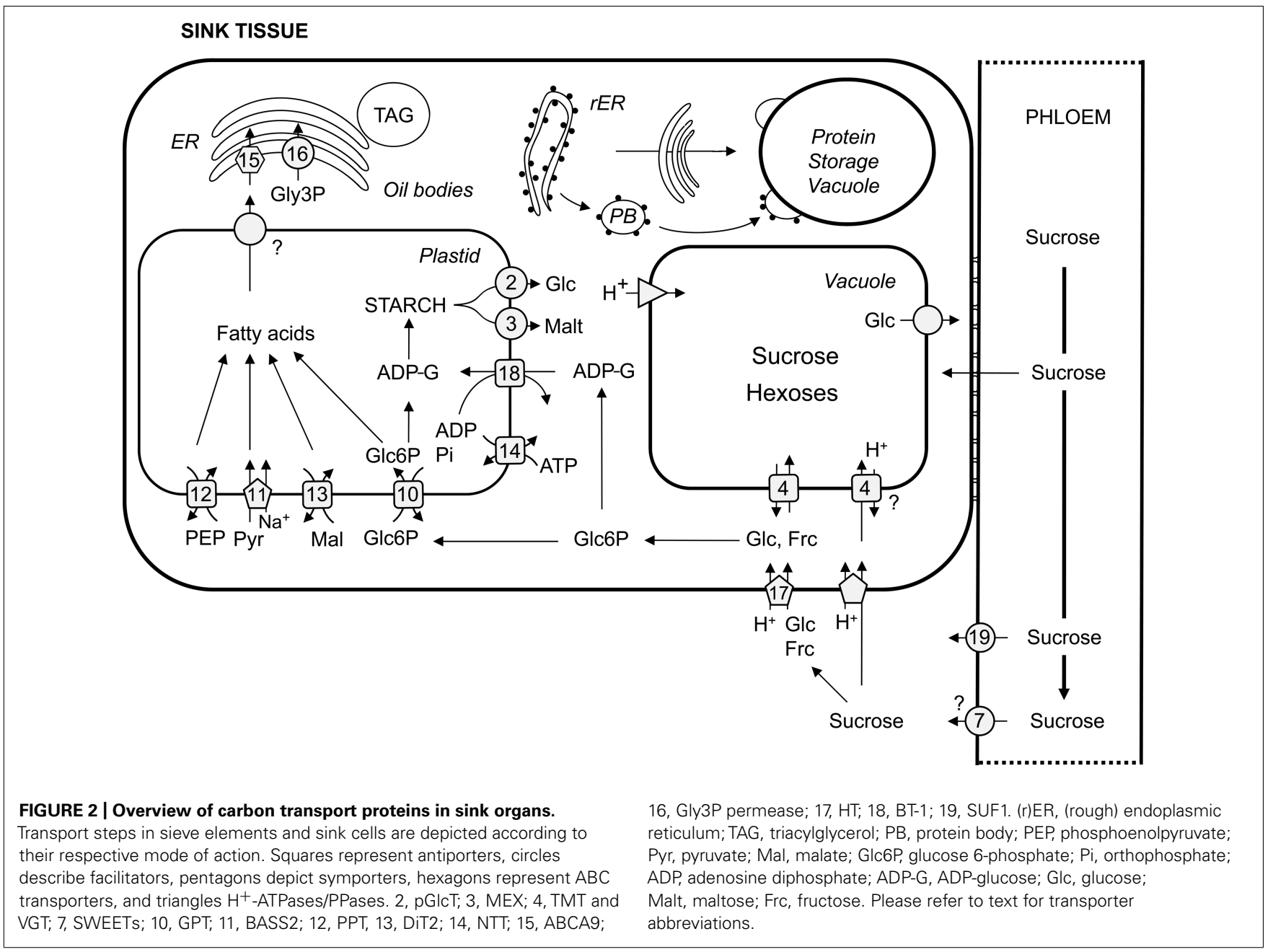


Kampfenkel etal., 1995) in counter-exchange with ADP and orthophosphate (Trentmann etal., 2008). Arabidopsis contains two NTTs and indeed $n t t 1 / n t t 2$ double mutants are impaired in seed protein and lipid contents and in seed yield (Reiser et al., 2004).

Fatty acids up to a length of 18 carbon atoms are produced in plastids. Incorporation of acylated fatty acids into TAG occurs in the ER (Li-Beisson et al., 2013). Hence, fatty acids have to be exported from plastids presumably by the recently identified fatty acid exporter FAX1 (K. Philippar, personal communication), and imported into the ER, and prior to incorporation into TAG have to be acylated by LACS proteins at the plastid outer envelope membrane (Shockey et al., 2002). To prevent inhibition of plastid metabolite transporters and thus fatty acid synthesis by cytosolic acyl-CoAs (Fox et al., 2001) and to assure efficient TAG production from acyl-CoAs, uptake into the ER should be rapid. Often reported spatial proximity of plastids or plastid stromules (filamentous tubules increasing the plastid surface area) and the ER (Schattat et al., 2011) might support a short retention time of acyl-CoA molecules in the cytosol. Recently, a transporter taking up free and acylated fatty acids into the ER has been described from Arabidopsis. The ABC transporter ABCA9 ("15" in Figure 2) has been found to localize to the ER, abca9 mutants had decreased seed weight, total lipid and TAG and were defective in effectively taking up ${ }^{14} \mathrm{C}$-labeled oleoyl-CoA and oleic acid. Moreover, constitutive overexpression of $A B C A 9$ driven by a constitutive promoter led to enlarged seeds with increased dry weight. The TAG content per seed was increased by $40 \%$ compared to wild-type. Since silique number per plant and seed number per silique were similar, overexpression of ABCA9 increased total seed oil per plant (Kim et al., 2013). This finding strongly argues for Arabidopsis yield to be sink-limited as it seems unlikely that the present expression of ABCA9 in leaves has a positive effect on source capacity. Moreover, it demonstrates that TAG production in the ER of embryo cells is limited by the supply with fatty acids rather than the Gly3P moiety of TAG. Nonetheless, Gly3P has to be imported into or present in the ER for TAG synthesis. This might be achieved by a member of the Gly3P permease family ("16" in Figure 2; Ramaiah et al., 2011), by phosphorylation of glycerol and/or by reduction of dihydroxyacetone phosphate. After having passed through the Kennedy pathway, synthesized TAG is stored in oil bodies (Hsieh and Huang, 2004; He and Wu, 2009) and can be used to fuel seedling establishment upon germination.

\section{SUGAR STORAGE IN PLANTS}

Some crop plants store sugars in tap roots, stems, and fruits, among them are sugar beet (Beta vulgaris), a member of the Amaranthaceae family, sugarcane (Saccharum hybrids) belonging to the Poaceae, grape (Vitis vinifera), a member of the Vitaceae family, and tomato (Solanum lycopersicum) belonging to the Solanaceae family. The former two species store sucrose whereas the latter two mainly store hexoses in vacuoles of roots, storage parenchyma, and fruit cells. Sucrose unloaded from the phloem has to reach these cells, and upon presence of an apoplastic step has to be imported into the cells either as sucrose or, when cleaved by an apoplastic invertase, as hexoses. Moreover, tonoplast transporters have to import sugars into the vacuole.
In young sugar beet tap roots growing with a rapid relative growth rate, sucrose unloaded from the phloem is cleaved by extracellular invertases indicating an apoplastic step in post-phloem transport. In older tap roots, invertase activities decrease and sucrose synthase activity increases (Klotz and Finger, 2002; Godt and Roitsch, 2006). Moreover, in experiments with ${ }^{14} \mathrm{C}$-labeled sucrose fed to mature tap root tissue, there was little evidence for a hydrolytic step preceding sucrose uptake. Furthermore, the uptake of sucrose occurs against a concentration gradient, and thus requires metabolic energy (Giaquinta, 1979; Wyse, 1979). Vacuolar ATPase inhibitors prevented uptake of sucrose whereas plasma membrane ATPase inhibitors did not (Saftner et al., 1983) indicating that post-phloem sucrose transport into storage cells of mature tap roots occurs symplastically whereas import into the vacuole is energized by a V-type $\mathrm{H}^{+}$-ATPase. This view is supported by analyses of tonoplast vesicles prepared from red beet root vacuoles which were found to hydrolyze ATP during sucrose transport (Getz, 1991). Sucrose-induced proton export occurred in a 1:1 stoichiometry (Getz and Klein, 1995) consistent with the idea of a sucrose $/ \mathrm{H}^{+}$-antiporter mediating the import of sucrose into storage vacuoles of sugar beet tap roots. Chiou and Bush (1996) described a tonoplast-localized transport protein expressed in leaves and tap roots. However, this transporter turned out to be a homolog of ERDL6, a vacuolar glucose exporter described above (Figure 2; Poschet et al., 2011).

In sugarcane, repeated sucrose breakdown and re-synthesis before storage in stem parenchyma cells has been described (Whittaker and Botha, 1997; Zhu etal., 1997). This "futile cycling" decreases with tissue maturity (Bindon and Botha, 2002; Uys et al., 2007). In mature internodes of stems sucrose seems to be symplastically unloaded since stem parenchyma cells are separated from the phloem by lignified and suberized cells preventing apoplastic unloading. Movement of the fluorescent tracer dye carboxyfluorescein from phloem to stem parenchyma cells indeed indicates symplastic connections. In younger internodes, a SUC2 ortholog is expressed in cells that are destined to be lignified (Rae et al., 2005) indicating an apoplastic step of sucrose unloading at this developmental stage. In mature internodes, sucrose was modeled to accumulate in vacuoles against a concentration gradient (Uys et al., 2007). This view was further substantiated by the detection of specialized acidic vacuoles with $\mathrm{V}$-type $\mathrm{H}^{+}$-ATPases in the stem (Rae et al., 2009), presumably maintaining the proton gradient that might be necessary to accumulate sucrose (against a concentration gradient) in a suggested proton antiport manner ("4" in Figure 2; Grof and Campbell, 2001). Both sugar beet and sugarcane have not been functionally analyzed regarding yield limitation, probably partially due to their resistance to be efficiently transformed.

Grape berries also undergo a developmental switch in unloading and post-phloem transport of sucrose. In contrast to sucrosestoring sugar beet and sugarcane, they shift from symplastic to apoplastic sucrose unloading upon onset of ripening as revealed by fluorescent dye analyses. Cell wall invertase activity increases at the onset of ripening, further substantiating apoplastic unloading at this developmental stage (Zhang et al., 2006). Moreover, Fillion et al. (1999) found that the STP-type hexose transporter VvHT1 ("17" in Figure 2) is expressed during ripening indicating 
that some of the sucrose might be apoplastically cleaved by cell wall invertases before being taken up into the cytosol. Sugars accumulate mainly as hexoses in vacuoles of berry cells upon onset of ripening (Davies and Robinson, 1996). In a comprehensive approach, Afoufa-Bastien et al. (2010) gave a phylogenetic overview on sugar transporters and also analyzed their expression. Upon the onset of ripening, several hexose transporters, TMTs and SUC11/12 were expressed in berries. SUC11/12 expression in ripening berries was also found in an independent study (Manning et al., 2001), and VvTMT2 (“4” in Figure 2) expression has also been identified as ripening-related by Cakir and Giachino (2012). Taken together, expression analyses of several transporters support the finding that vacuolar storage of hexoses occurs by a switch to apoplastic unloading of sucrose upon onset of berry ripening. However, whether source- or sink capacity determines yield of grape berries remains elusive.

Tomato fruits and grape berries behave similarly with respect to sucrose unloading and post-phloem transport. In young tomato fruits, when starch content is built up in plastids of the columella and inner pericarp region of the fruit (Robinson et al., 1988; Schaffer and Petreikov, 1997), unloading is mainly symplastic. Upon the developmental shift to rapid hexose accumulation, also in the outer pericarp region, an apoplastic step is likely to occur (Ruan and Patrick, 1995) and is linked to an energized uptake of hexoses (“17” in Figure 2; Damon et al., 1988; Ruan et al., 1997) and sucrose (Figure 2; Damon et al., 1988). Similar to sugarcane, "futile cycles" involving invertase, sucrose synthase and starch synthesis and degradation seem to be abundant in tomato fruits to sustain sink capacity (Nguyen-Quoc and Foyer, 2001). The importance of transient starch accumulation for yield - unlike the above mentioned Brassicaceae seeds - was demonstrated by Baxter et al. (2005) who analyzed an introgression line with a fruit apoplastic invertase from the wild species Solanum pennellii introgressed into Solanum lycopersicum. Here, a dramatic increase in starch accumulation in early developmental stages was observed pointing toward partial apoplastic unloading already at younger developmental stages. Introgression lines had higher total soluble solids (TSS), a major determinant of fruit quality for processing (Baxter et al., 2005). More direct evidence for the importance of transient starch accumulation has been obtained by Petreikov et al. (2009) who developed and characterized introgression lines of Solanum lycopersicum harboring a wild species Solanum habrochaites allele for the regulatory large subunit of AGPase. This led to a large transient increase in starch which accounted for the enhanced amount of TSS and also an increase in fruit size. However, when hexose transporter- (STP-type) mediated uptake of hexoses from the apoplast was impaired by antisense expression of tomato HT1, HT2, and HT3 ("17" in Figure 2; McCurdy et al., 2010), yield was decreased. Taken together, these findings point toward tomato yield being limited by sink capacity that can be increased when limitations of photoassimilate import into fruits are abolished.

\section{STARCH STORAGE IN PLANTS}

Apart from soybean and sugarcane, the most important crops store starch, among them the grasses corn (Zea mays), rice (Oryza sativa), and wheat (Triticum aestivum) belonging to the Poaceae family, and potato (Solanum tuberosum), a member of the Solanaceae family. Other starch-storing staple foods are yams (Dioscorea sp.), belonging to the Dioscoreaceae, or cassava (Manihot esculenta), a member of the Euphorbiaceae. Grasses store starch in the endosperm of their caryopses, popularly called the "grain." Potato, yams, and cassava store starch in tubers, the former tuber is derived from the sprout, the two latter tubers from roots.

In grasses, sucrose released from the phloem in grains symplastically reaches the maternal side of the maternal/filial interface, in wheat described as nucellar projection (Fisher and Cash-Clark, 2000; Patrick and Offler, 2001; Krishnan and Dayanandan, 2003). At the interface which appears as an endosperm cavity in wheat grains, cells can specialize on the maternal, as well as, on the filial side to transfer cells (characterized by cell wall in growths) to maximize plasma membrane size for release and uptake of sugars. In corn missing such an endosperm cavity, the filial cells can undergo specialization to transfer cells (Patrick and Offler, 2001; Gómez et al., 2002; Krishnan and Dayanandan, 2003). It can be hypothesized that sugar unloading is mediated by SWEETs (" 7 " in Figure 2). To enter the filial tissue, sugars have to be taken up from the apoplast, likely to be mediated by sucrose- or hexose $/ \mathrm{H}^{+}$symporters (Figure 2). In the endosperm, symplastic connections between uptake and storage cells exist (Patrick and Offler, 2001).

In cereal endosperm, starch synthesis differs from other starchstoring organs in that most of the AGPase activity is extraplastidic, i.e., cytosolic (Denyer et al., 1996; Thorbjörnsen et al., 1996; Beckles et al., 2001; James et al., 2003), requiring an additional uptake system for carbon skeletons into plastids supplementary to the GPT ("10" in Figure 2; Kammerer et al., 1998). Externally supplied ADP-glucose (ADP-G) was found to drive starch synthesis in isolated maize endosperm amyloplasts (Möhlmann et al., 1997) while Shannon et al. (1998) found Brittle-1 (BT-1; "18” in Figure 2; Sullivan and Kaneko, 1995) to be responsible for the uptake of ADP-G into maize endosperm amyloplasts by including the $b t-1$ mutant in the analyses. Direct uptake measurements with the BT1 from maize endosperm heterologously expressed in Escherichia coli cells revealed ADP-G uptake in counter-exchange with ADP (Kirchberger et al., 2007). Several approaches to increase starch yield of wheat and corn grains were successful when cytosolic AGPase activity was increased (Smidansky et al., 2002; Wang et al., 2007; Li et al., 2011), indicating that ADP-G import and thus BT-1 activity might not be limiting for starch yield. However, in contrast to the notion that photosynthesis is the limiting factor for increased yield (e.g., Long et al., 2006; Makino, 2011), these results suggest that sink- rather than source capacity limits grain starch yield in cereals.

In potato, starch is stored in tubers from which the plant can vegetatively, i.e., clonally propagate without a filial generation. Tubers are formed from stolons, below-ground lateral shoots. Upon induction of tuberization (Rodríguez-Falcón et al., 2006), stolons start to swell at their apical hook. In non-tuberized stolons, sucrose transported in the phloem is unloaded apoplastically. This view is supported by experiments using carboxyfluorescein trapped in the phloem and ${ }^{14} \mathrm{C}$-labeled assimilates, mainly sucrose, which were evenly distributed in the stolon, i.e., also outside the phloem. Upon tuberization, carboxyfluorescein was able to leave the phloem, but only in the swollen part of the 
stolon, indicative for symplastic unloading. Taken together, tuberization involves a switch from apoplastic to symplastic phloem unloading (Viola et al., 2001). However, this switch is likely to be incomplete because otherwise an impact of apoplastically localized yeast invertase expressed under control of a tuber-specific promoter on metabolism could not be explained (Sonnewald et al., 1997; Hajirezaei et al., 2000). Alternatively, symplastically unloaded sucrose might leak out of sink cells. Again, a yet to be identified member of the SWEET family transporter (" 7 " in Figure 2) may be discussed as the facilitator of apoplastic phloem unloading or as the transporter mediating leakage of sucrose. Whether mainly sucrose or hexoses - produced from sucrose by cell wall invertases - are imported into sink cells probably by sucrose- or hexose $/ \mathrm{H}^{+}$-symporters (Figure 2) remains to be elucidated. It is also unknown which transporters are engaged in this process. Sucrose entering sink cells via the apoplast or plasmodesmata might be further metabolized by sucrose synthase, since invertase activity is gradually reduced, while sucrose synthase activity yielding UPG-glucose and fructose increased during development (Hajirezaei etal., 2000). A part of the imported sucrose is further used to drive energy production indispensable for anabolic processes such as starch synthesis in heterotrophic tuber tissue. To synthesize starch, carbon skeletons and energy are imported into amyloplasts. Glc6P is imported by a GPT ("10" in Figure 2) in counter-exchange with orthophosphate or triose phosphate, and ATP generated in mitochondria is imported by the adenylate translocator NTT ("14" in Figure 2) in counterexchange with ADP and orthophosphate. Shortage of energy import into amyloplasts as revealed by antisense repression of the adenylate translocator, led to compromised tuber starch content and yield (Tjaden et al., 1998). Overexpression, however, had no impact on starch yield, irrespective of the promoter, constitutive (Tjaden et al., 1998) or tuber-specific (Zhang et al., 2008), that drove expression of the transgene. Tuber-specific overexpression of a pea GPT also had no impact on tuber starch yield. Only when both carbon and energy supply to plastids was increased simultaneously, mediated by overexpression of GPT and NTT, tuber starch content and yield increased (Zhang et al., 2008). This indicated that import of carbon and energy co-limit starch yield which appears sink- rather than source-limited under these growth conditions. Moreover, a combined enhancement of sink- and source capacities led to even higher starch yield of triple-transgenic potato plants. The overexpression of GPT and NTT in tubers and additionally either overexpression of an Escherichia coli pyrophosphatase in mesophyll cytosol or reduced AGPase activity in leaves increased sucrose synthesis in source tissues (Jonik et al., 2012). Without simultaneously increasing sink capacity, neither leafspecific antisense repression of AGPase (Leidreiter et al., 1995) nor mesophyll-specific cytosolic overexpression of pyrophosphatase (Jonik et al., 2012) - the latter analyzed in field trials and in the greenhouse - led to an increase in tuber starch yield indicating once more that potato tuber starch yield is sink-limited.

\section{PROTEIN STORAGE IN PLANTS}

Members of the Fabaceae family store protein in their seeds, which represent the main plant source for human nitrogen nutrition. However, soybean (G. max) is primarily grown to provide oil from seeds, and pea (Pisum sativum) seeds contain more starch than protein. Other crop members of the family are bean (Phaseolus vulgaris), chickpea (Cicer arietinum), and peanut (Arachis hypogaea). There are species of families other than Fabaceae which contain reasonable amounts of storage protein in their harvested organs. However, these are mainly grown for their starch (e.g., potato, corn) or oil (e.g., canola). In order to store protein ample nitrogen must be available. Consistently, members of the Fabaceae family living in symbiosis with rhizobial bacteria store protein in seeds as the symbiotic bacteria fix atmospheric molecular nitrogen and supply the host plant with sufficient reduced nitrogen.

In legumes, protein is stored in the embryo in structures known as protein storage vacuoles. Storage proteins are translated at the ribosomes of the rough ER and are co-translationally imported into the ER. The main route from the ER to protein storage vacuoles is via the Golgi (Herman and Larkins, 1999). However, the alternative pathway, protein bodies budding off the ER and either remaining in the cytosol or fusing with the protein storage vacuole (as previously described in cereals) also seems to exist in legumes (Figure 2; Herman and Larkins, 1999; Vitale and Ceriotti, 2004; Abirached-Darmency et al., 2012).

Sucrose (and amino acid) unloading from the phloem in legume seeds occurs symplastically. Analyses with fluorescent dyes indicate that sucrose is symplastically transported to the maternal release site, the ground- or thin-walled parenchyma (Tegeder et al., 1999; van Dongen et al., 2003). Sucrose is either simply or through specialized transfer cells released into the apoplast dependent on the legume species (Patrick and Offler, 2001; van Dongen et al., 2003). At the younger stages, legume seeds contain a liquid endosperm which acts as a buffer for sucrose and glutamine for the developing embryo (Melkus et al., 2009). At the expense of embryo growth, the endosperm is substantially degraded during development (Patrick and Offler, 2001). At later developmental stages, sucrose is released from maternal tissue to the apoplast and is taken up by embryo epidermal transfer cells (Weber et al., 1997; Tegeder et al., 1999). With the discovery of a new class of sucrose facilitators from pea and bean, called SUFs, expressed at the maternal release site, sucrose release into the apoplast is probably mediated by these transporters ("19" in Figure 2; Zhou et al., 2007). In these same cells, the sucrose $/ \mathrm{H}^{+}$-symporter SUT1 was found to be expressed and believed to likely function in seed coat sucrose retrieval (Tegeder et al., 1999; Zhou et al., 2007). At the filial side, uptake of sucrose by the embryo epidermis is mediated by SUT1 (Figure 2), and uptake is energized by P-type $\mathrm{H}^{+}$-ATPases which are both co-expressed in embryo transfer cells (Tegeder et al., 1999). The embryo communicates the demand for sucrose uptake from the apoplast by the internal sugar level. Sucrose uptake fluxes have been found to be negatively correlated with pool sizes of intracellular sugars, while SUT1 transcripts were sensitive to sugar levels (i.e., when the embryo contains sufficient sugars, SUT1 is transcriptionally down-regulated), which in turn led to decreased sucrose uptake (Zhou et al., 2009). To increase the uptake of sucrose into pea embryos, potato SUT1 was overexpressed using a storage parenchyma-specific promoter which resulted in increased sucrose uptake and accelerated growth rates of the embryo. However, final seed weight of transgenic plants was 
similar to the wild-type. The authors speculate that overexpression at the primary site of sucrose uptake, the epidermal transfer cells, might have led to more significant results (Rosche et al., 2002). In a different transgenic approach, seed protein content in mature seeds was increased. Rolletschek et al. (2007) antisense inhibited the Vicia narbonensis GPT1 ("10" in Figure 2) using a seed-specific promoter. As expected, flux of carbon into plastids and thus into starch and (mainly structural) lipids was found to be decreased. A simultaneous increase in seed protein, however, was not predictable. The authors explain this finding with increased expression of the amino acid permease $A A P 1$ in transgenic embryos potentially due to lower glutamine concentrations during the main protein storage phase. Glutamine was previously described to repress AAP1 transcriptionally (Miranda et al., 2001). Indeed, when AAP1 was overexpressed in seeds of Vicia narbonensis and pea, sink strength for amino acids was increased and the

\section{REFERENCES}

Abirached-Darmency, M., Dessaint, F., Benlicha, E., and Schneider, C. (2012). Biogenesis of protein bodies during vicilin accumulation in Medicago truncatula immature seeds. BMC Res. Notes 5:409. doi: 10.1186/1756-0500-5-409

Afoufa-Bastien, D., Medici, A., Jeauffre, J., Coutos-Thévenot, P., Lemoine, R., Atanassova, R., et al. (2010). The Vitis vinifera sugar transporter gene family: phylogenetic overview and macroarray expression profiling. BMC Plant Biol. 10:245. doi: 10.1186/1471-2229-10-245

Ainsworth, E. A., and Bush, D. R. (2011). Carbohydrate export from the leaf: a highly regulated process and target to enhance photosynthesis and productivity. Plant Physiol. 155, 64-69. doi: 10.1104/ pp.110.167684

Aluri, S., and Büttner, M. (2007). Identification and functional expression of the Arabidopsis thaliana vacuolar glucose transporter 1 and its role in seed germination and flowering. Proc. Natl. Acad. Sci. U.S.A. 104, 2537-2542. doi: 10.1073/pnas. 0610278104

Andriotis, V. M. E., Pike, M. J., Kular, B., Rawsthorne, S., and Smith, A. M. (2010a). Starch turnover in developing oilseed embryos. New Phytol. 187, 791-804. doi: 10.1111/j.14698137.2010.03311.x

Andriotis, V. M. E., Pike, M. J., Bunnewell, S., Hills, M. J., and Smith, A. M. (2010b). The plastidial glucose6-phosphate/phosphate antiporter GPT1 is essential for morphogenesis in Arabidopsis embryos. Plant J. 64, 128-139. doi: 10.1111/j.1365-313X. 2010.04313.x

Andriotis, V. M. E., Pike, M. J., Schwarz, S. L., Rawsthorne, S., Wang, T. L., and Smith, A. M. (2012). Altered starch turnover in the maternal plant has major effects on Arabidopsis fruit growth and seed composition. Plant Physiol. 160, 1175-1186. doi: 10.1104/pp.112.205062

Antony, G., Zhou, J., Huang, S., Li, T., Liu, B., White, F., et al. (2010) Rice xa13 recessive resistance to bacterial blight is defeated by induction of the disease susceptibility gene Os11N3. Plant Cell 22, 3864-3876. doi: 10.1105/tpc.110.078964

Ayre, B. G. (2011). Membranetransport systems for sucrose in relation to whole-plant carbon partitioning. Mol. Plant 4, 377-394. doi: $10.1093 / \mathrm{mp} / \mathrm{ssr} 014$

Baker, R. F., Leacvh, K. A., and Braun, D. M. (2012). SWEET as sugar: new sucrose effluxers in plants. Mol. Plant 5, 766-768. doi: $10.1093 / \mathrm{mp} /$ SSS054

Barth, I., Meyer, S., and Sauer, N. (2003). PmSUC3: characterization of a SUT2/SUC3-type sucrose transporter from Plantago major. Plant Cell 15, 1375-1385. doi: 10.1105/tpc.010967

Baud, S., Boutin, J.-P., Miquel, M. Lepiniec, L., and Rochat, C. (2002). An integrated overview of seed development in Arabidopsis thaliana ecotype WS. Plant Physiol. Biochem. 40, 151160. doi: 10.1016/S0981-9428(01) 01350-X

Baud, S., Wuillème, S., Lemoine, R., Kronenberger, J., Caboche, M., Lepiniec, L., etal. (2005). The AtSUC5 sucrose transporter specifically expressed in the endosperm is involved in early seed development in Arabidopsis. Plant J. 43, 824-836.

Baxter, C. J., Carrari, F., Bauke, A., Overy, S., Hill, S. A., Quick, P. W., etal. (2005). Fruit carbohydrate metabolism in an introgressed

amounts of total nitrogen and protein (mainly storage globulins) were increased (Rolletschek et al., 2005).

\section{CONCLUDING REMARKS}

This review on plant carbon allocation and transport unequivocally demonstrates the increasing importance of sub- and intercellular, as well as, long-distance transport processes. Given the impact of several of the described modifications on yield of various crop plants, we suggest continued work on several of the insinuated and not yet conceived transport steps within plants which frequently turn out to be the rate-limiting steps for the production of valuable compounds in storage sinks.

\section{ACKNOWLEDGMENT}

We are grateful to Dr. Karl Pioch for critically reading the manuscript.

line of tomato with increased fruit soluble solids. Plant Cell Physiol. 46, 425-437. doi: 10.1093/pcp/pci040

Beckles, D. M., Smith, A. M., and ap Rees, T. (2001). A cytosolic ADPglucose pyrophosphorylase is a feature of graminaceous endosperms, but not of other starch-storing organs. Plant Physiol. 125, 818-827. doi: 10.1104/pp.125.2.818

Bindon, K. A., and Botha, F. C. (2002). Carbon allocation to the insoluble fraction, respiration and triosephosphate cycling in the sugarcane culm. Physiol. Plant. 116,1219. doi: $10.1034 / \mathrm{j} .1399-3054.2002$. 1160102.x

Braun, D. M. (2012). SWEET! The pathway is complete. Science 335, 173-174. doi: 10.1126/science. 1216828

Bürkle, L., Hibberd, J., Quick, W. P., Kühn, C., Hirner, B., and Frommer, W. B. (1998). The H+-sucrose cotransporter NtSUT1 is essential for sugar export from tobacco leaves. Plant Physiol. 118, 59-68.

Bush, D. R. (1989). Proton-coupled sucrose transport in plasmalemma vesicles isolated from sugar beet (Beta vulgaris L. cv Great Western) leaves. Plant Physiol. 89, 13181323. doi: $10.1104 /$ pp.89.4.1318

Büttner, M. (2007). The monosaccharide transporter(-like) gene family in Arabidopsis. FEBS Lett. 581, 23182324.

Büttner, M. (2010). The Arabidopsis sugar transporter (AtSTP) family: an update. Plant Biol. Suppl. 1, 35-41. doi: 10.1111/j.14388677.2010.00383.x

Cakir, B., and Giachino, R. R. A. (2012). VvTMT2 encodes a putative tonoplast monosaccharide transporter expressed during grape berry (Vitis vinifera cv. Sultanine) ripening. Plant Omics J. 5, 576-583.
Caspar, T., Huber, S. C., and Somerville, C. (1985). Alterations in growth, photosynthesis, and respiration in a starchless mutant of Arabidopsis thaliana (L.) deficient in chloroplast phosphoglucomutase activity. Plant Physiol. 79, 11-17. doi: 10.1104/pp.79.1.11

Chardon, F., Bedu, M., Calenge, F., Klemens, P. A. W., Spinner, L., Clement, G., et al. (2013). Leaf fructose content is controlled by the vacuolar transporter SWEET17 in Arabidopsis. Curr. Biol. 23, 697-702. doi: 10.1016/j.cub.2013.03.021

Chen, L.-Q., Hou, B.-H., Lalonde, S., Takanaga, H., Hartung, M. L., Qu, X.-Q., et al. (2010). Sugar transporters for intercellular exchange and nutrition of pathogens. Nature 468, 527-534. doi: 10.1038/ nature09606

Chen, L.-Q., Qu, X.-Q., Hou, B.-H., Sosso, D., Osorio, S., Fernie, A. R., et al. (2012). Sucrose efflux mediated by SWEET proteins as a key step for phloem transport. Science 335, 207-211. doi: 10.1126/science. 1213351

Chincinska, I. A., Liesche, J., Krügel, U., Michalska, J., Geigenberger, P., Grimm, B., et al. (2008). Sucrose transporter StSUT4 from potato affects flowering, tuberization, and shade avoidance response. Plant Physiol. 146, 515-528.

Chiou, T. J., and Bush, D. R. (1996). Molecular cloning, immunochemical localization to the vacuole, and expression in transgenic yeast and tobacco of a putative sugar transporter from sugar beet. Plant Physiol. 110, 511-520. doi: 10.1104/pp.110.2.511

Cho, M.-H., Jang, A., Bhoo, S. H., Jeon, J.-S., and Hahn, T.-R. (2012). Manipulation of triose phosphate/phosphate translocator 
and cytosolic fructose-1,6bisphosphatase, the key components in photosynthetic sucrose synthesis, enhance the source capacity of transgenic Arabidopsis plants. Photosynth. Res. 111, 261-268. doi: 10.1007/s11120-012-9720-2

Cho, M.-H., Lim, H., Shin, D. H., Jeon, J.-S., Bhoo, S. H., Park, Y.I., et al. (2011). Role of plastidic glucose transporters in the export of starch degradation products from the chloroplasts in Arabidopsis thaliana. New Phytol. 190, 101112. doi: $10.1111 /$ j.1469-8137.2010. 03580.x

Damon, S., Hewitt, J., Nieder, M., and Bennett, A. B. (1988). Sink metabolism in tomato fruit. II. Phloem unloading and sugar uptake. Plant Physiol. 87, 731-736. doi: 10.1104/pp.87.3.731

da Silva, P. M. F. R., Eastmond, P. J., Hill, L. M., Smith, A. M., and Rawsthorne, S. (1997). Starch metabolism in developing embryos of oilseed rape. Planta 203, 480-487. doi: 10.1007/s004250050217

Davies, C., and Robinson, S. P. (1996). Sugar accumulation in grape berries. Cloning of two putative vacuolar invertase cDNAs and their expression in grapevine tissues. Plant Physiol. 111, 275-283. doi: 10.1104/pp.111.1.275

Delrot, S., and Bonnemain, J.-L. (1981). Involvement of protons as a substrate for the sucrose carrier during phloem loading in Vicia faba leaves. Plant Physiol. 67, 560-564. doi: 10.1104/pp.67.3.560

Denyer, K., Dunlap, F., Thorbjörnsen, T., Keeling, P., and Smith, A. M. (1996). The major form of ADPglucose pyrophosphorylase in maize endosperm is extra-plastidial. Plant Physiol. 112, 779-785.

Dickinson, C. D., Altabella, T., and Chrispeels, M. J. (1991). Slowgrowth phenotype of transgenic tomato expressing apoplastic invertase. Plant Physiol. 95, 420-425. doi: 10.1104/pp.95.2.420

Eastmond, P. J., and Rawsthorne, S. (2000). Coordinate changes in carbon partitioning and plastidial metabolism during the development of oilseed rape embryos. Plant Physiol. 122, 767-774. doi: 10.1104/pp.122.3.767

Endler, A., Meyer, S., Schelbert, S., Schneider, T., Weschke, W., Peters, S. W., et al. (2006). Identification of a vacuolar sucrose transporter in barley and Arabidopsis mesophyll cells by a tonoplast proteomic approach. Plant Physiol. 141, 196-207. doi: 10.1104/pp.106.079533
Eom, J.-S., Cho, J.-I., Reinders, A., Lee, S.-W., Yoo, Y., Tuan, P. Q., et al. (2011). Impaired function of the tonoplast-localized sucrose transporter in rice, OsSUT2, limits the transport of vacuolar reserve sucrose and affects plant growth. Plant Physiol. 157, 109-119. doi: 10.1104/pp. 111.176982

Fillion, L., Ageorges, A., Picaud, S., Coutos-Thévenot, P., Lemoine, R., Romieu, C., etal. (1999). Cloning and expression of a hexose transporter gene expressed during ripening of grape berry. Plant Physiol. 120, 1083-1093.

Fischer, K., Kammerer, B., Gutensohn, M., Arbinger, B., Weber, A., Häusler, R. E., et al. (1997). A new class of plastidic phosphate translocators: a putative link between primary and secondary metabolism by the phosphoenolpyruvate/phosphate antiporter. Plant Cell 9, 453-462.

Fisher, D. B., and Cash-Clark, C. E. (2000). Sieve tube unloading and post-phloem transport of fluorescent tracers and proteins injected into sieve tubes via severed aphid stylets. Plant Physiol. 123, 125-137. doi: 10.1104/pp.123.1.125

Fliege, R., Flügge, U.-I., Werdan, K., and Heldt, H. W. (1978). Specific transport of inorganic phosphate, 3-phosphoglycerate and triosephosphates across the inner membrane of the envelope in spinach chloroplasts. Biochim. Biophys. Acta 502, 232-247.

Flügge, U.-I., Fischer, K., Gross, A., Sebald, W., Lottspeich, F., and Eckerskorn, C. (1989). The triose phosphate-3-phosphoglycerate-

phosphate translocator from spinach chloroplasts: nucleotide sequence of a full-length cDNA clone and import of the in vitro synthesized precursor protein into chloroplasts. EMBO J. 8, 39-46.

Flügge, U.-I., Häusler, R. E., Ludewig, F., and Gierth, M. (2011). The role of transporters in supplying energy to plant plastids. J. Exp. Bot. 62, 2381-2392. doi: 10.1093/jxb/ erq361

Fondy, B. R., and Geiger, D. R. (1977). Sugar selectivity and other characteristics of phloem loading in Beta vulgaris L. Plant Physiol. 59, 953-960. doi: 10.1104/pp.59. 5.953

Fox, S. R., Rawsthorne, S., and Hills, M. J. (2001). Fatty acid synthesis in pea root plastids is inhibited by the action of long-chain acyl-coenzyme as on metabolite transporters. Plant Physiol. 126, 1259-1265. doi: 10.1104/pp. 126.3.1259
Furumoto, T., Yamaguchi, T., Ohshima-Ichie, Y., Nakamura, M., Tsuchida-Iwata, Y., Shimamura, M., et al. (2011). A plastidial sodium-dependent pyruvate transporter. Nature 476, 472-475. doi: 10.1038 /nature 10250

Gahrtz, M., Stolz, J., and Sauer, N. (1994). A phloem-specific sucrose$\mathrm{H}+$ symporter from Plantago major L. supports the model of apoplastic phloem loading. Plant J. 6, 697-706. doi: 10.1046/j.1365313X.1994.6050697.x

Getz, H. P. (1991). Sucrose transport in tonoplast vesicles of red beet roots is linked to ATP hydrolysis. Planta 185, 261-268. doi: 10.1007/ BF00194069

Getz, H. P., and Klein, M. (1995). Characteristics of sucrose transport and sucrose-induced $\mathrm{H}+$ transport on the tonoplast of red beet (Beta vul garis L.) storage tissue. Plant Physiol. 107, 459-467.

Giaquinta, R. (1977a). Phloem loading of sucrose. $\mathrm{pH}$ dependency and selectivity. Plant Physiol. 59, 750-755. doi: 10.1104/pp.59.4.750

Giaquinta, R. (1977b). Possible role of $\mathrm{pH}$ gradient and membrane ATPase in the loading of sucrose into the sieve tubes. Nature 267, 369-370. doi: $10.1038 / 267369 \mathrm{a} 0$

Giaquinta, R. T. (1979). Sucrose translocation and storage in the sugar beet. Plant Physiol. 63, 828-832. doi: $10.1104 /$ pp.63.5.828

Godt, D., and Roitsch, T. (2006). The developmental and organ specific expression of sucrose cleaving enzymes in sugar beet suggests a transition between apoplasmic and symplasmic phloem unloading in the tap roots. Plant Physiol. Biochem. 44, 656-665. doi: 10.1016/j.plaphy.2006. 09.019

Gómez, E., Royo, J., Guo, Y., Thompson, R., and Hueros, G. (2002). Establishment of cereal endosperm expression domains: identification and properties of a maize transfer cell-specific transcription factor, ZmMRP-1. Plant Cell 14, 599-610.

Gottwald, J. R., Krysan, P. J., Young, J. C., Evert, R. F., and Sussman, M. R. (2000). Genetic evidence for the in planta role of phloem-specific plasma membrane sucrose transporters. Proc. Natl. Acad. Sci. 97, 13979-13984. doi: 10.1073/pnas. 250473797

Gould, N., Thorpe, M. R., Pritchard, J., Christeller, J. T., Williams, L. E., Roeb, G., et al. (2012). AtSUC2 has a role for sucrose retrieval along the phloem pathway: evidence from carbon-11 tracer studies. Plant Sci. 188-189, 97-101. doi: 10.1016/j.plantsci.2011.12.018

Grof, C. P. L., and Campbell, J. A. (2001). Sugarcane sucrose metabolism: scope for molecular manipulation. Aust. J. Plant Physiol. 28, 1-12.

Hafke, J. B., van Amerongen, J.-K., Kelling, F., Furch, A. C. U., Gaupels, F., and van Bel, A. J. E. (2005). Thermodynamic battle for photosynthate acquisition between sieve tubes and adjoining parenchyma in transport phloem. Plant Physiol. 138, 1527-1537. doi: 10.1104/pp.104. 058511

Hajirezaei, M.-R., Takahata, Y., Trethewey, R. N., Willmitzer, L., and Sonnewald, U. (2000). Impact of elevated cytosolic and apoplastic invertase activity on carbon metabolism during potato tuber development. J. Exp. Bot. 51, 439-445. doi: 10.1093/jexbot/ 51.suppl_1.439

Häusler, R. E., Schlieben, N. H., Nicolay, P., Fischer, K., Fischer, K. L., and Flügge, U.-I. (2000). Control of carbon partitioning and photosynthesis by the triose phosphate/phosphate translocator in transgenic tobacco plants (Nicotiana tabacum L.). I. Comparative physiological analysis of tobacco plants with antisense repression and overexpression of the triose phosphate/phosphate translocator. Planta 210, 371-382.

Häusler, R. E., Schlieben, N. H., Schulz, B., and Flügge, U.-I. (1998). Compensation of decreased triose phosphate/phosphate translocator activity by accelerated starch turnover and glucose transport in transgenic tobacco. Planta 204, 366-376.

He, Y.-Q., and Wu, Y. (2009). Oil body biogenesis during Brassica napus embryogenesis. J. Integr. Plant Biol. 51, 792-799. doi: 10.1111/j.17447909.2009.00851.x

Heineke, D., Kruse, A., Flügge, U.I., Frommer, W. B., Riesmeier, J. W., Willmitzer, L., et al. (1994). Effect of antisense repression of the chloroplast triose-phosphate translocator on photosynthetic metabolism in transgenic potato plants. Planta 193, 174-180.

Heineke, D., Sonnewald, U., Büssis, D., Günter, G., Leidreiter, K., Wilke, I., et al. (1992). Apoplastic expression of yeast-derived invertase in potato: effects on photosynthesis, leaf solute composition, water relations, and tuber composition. Plant Physiol. 100, 301-308.

Herman, E. M., and Larkins, B. A. (1999). Protein storage bodies and vacuoles. Plant Cell 11, 601-613. 
Hsieh, K., and Huang, A. H. C. (2004). Endoplasmic reticulum, oleosins, and oils in seeds and tapetum cells. Plant Physiol. 136, 3427-3434. doi: 10.1104/pp.104.051060

Imlau, A., Truernit, E., and Sauer, N. (1999). Cell-to-cell and long-distance trafficking of the green fluorescent protein in the phloem and symplastic unloading of the protein into sink tissues. Plant Cell 11, 309-322.

James, M. G., Denyer, K., and Myers, A. M. (2003). Starch synthesis in the cereal endosperm. Curr. Opin. Plant Biol. 6, 215-222. doi: 10.1016/S13695266(03)00042-6

Jonik, C., Sonnewald, U., Hajirezaei, M. R., Flügge, U.-I., and Ludewig, F. (2012). Simultaneous boosting of source and sink capacities doubles tuber starch yield of potato plants. Plant Biotechnol. J. 10, 10881098. doi: 10.1111/j.1467-7652.2012. 00736.x

Kammerer, B., Fischer, K., Hilpert, B., Schubert, S., Gutensohn, M., Weber, A., et al. (1998). Molecular characterization of a carbon transporter in plastids from heterotrophic tissues: the glucose 6-phosphate/phosphate antiporter. Plant Cell 10,105-117.

Kampfenkel, K., Möhlmann, T., Batz, O., van Montagu, M., Inzé, D., and Neuhaus, H. E. (1995). Molecular characterization of an Arabidopsis thaliana cDNA encoding a novel putative adenylate translocator of higher plants. FEBS Lett. 374, 351-355.

Kempers, R., Ammerlaan, A., and van Bel, A. J. E. (1998). Symplasmic constriction and ultrastructural feature of the sieve element/companion cell complex in the transport phloem of apoplasmically and symplasmically phloem-loading species. Plant Physiol. 116, 271-278. doi: 10.1104/pp.116.1.271

Kennedy, E. P. (1961). Biosynthesis of complex lipids. Fed. Proc. 20, 934 940.

Kim, S., Yamaoka, Y., Ono, H., Kim, H., Shim, D., Maeshima, M., et al. (2013). AtABCA9 transporter supplies fatty acids for lipid synthesis to the endoplasmic reticulum. Proc. Natl. Acad. Sci. U.S.A. 110, 773-778. doi: 10.1073/pnas. 1214159110

Kirchberger, S., Leroch, M., Huynen, M. A., Wahl, M., Neuhaus, H. E., and Tjaden, J. (2007). Molecular and biochemical analysis of the plastidic ADP-glucose transporter (ZmBT1) from Zea mays. J. Biol. Chem. 282, 22481-22491. doi: 10.1074/jbc.M702484200

Klotz, K. L., and Finger, F. L. (2002). Contribution of invertase and sucrose synthase isoforms to sucrose catabolism in developing sugarbeet roots. J. Sugar Beet Res. 39, 1-24. doi: 10.5274/jsbr.39.1.1

Komor, E., Rotter, M., and Tanner W. (1977). A proton-cotransport system in a higher plant: sucrose transport in Ricinus communis. Plant Sci. Lett. 9, 153-162. doi: 10.1016/03044211(77)90093-1

Krishnan, S., and Dayanandan, P. (2003). Structural and histochemical studies on grain-filling in the caryopsis of rice (Oryza sativa L.). J. Biosci. 28, 455-469. doi: 10.1007/BF02705120

Kühn, C., and Grof, C. P. L. (2010). Sucrose transporters of higher plants. Curr. Opin. Plant Biol. 13, 288-298. doi: 10.1016/j.pbi.2010. 02.001

Kühn, C., Quick, W. P., Schulz, A., Sonnewald, U., and Frommer, W. B. (1996). Companion cell-specific inhibition of the potato sucrose transporter SUT1. Plant Cell Environ. 19, 1115-1123. doi: 10.1111/j.13653040.1996.tb00426.x

Leggewie, G., Kolbe, A., Lemoine, R., Roessner, U., Lytovchenko, A. Zuther, E., et al. (2003). Overexpression of the sucrose transporter SoSUT1 in potato results in alterations in leaf carbon partitioning and in tuber metabolism but has little impact on tuber morphology. Planta 217, 158-167.

Leidreiter, K., Heineke, D., Heldt, H. W. Müller-Röber, B., Sonnewald, U., and Willmitzer, L. (1995). Leaf-specific antisense inhibition of starch biosynthesis in transgenic potato plants leads to an increase in photoassimilate export from source leaves during the light period. Plant Cell Physiol. 36, 615-624

Li, H. M., Culligan, K., Dixon, R. A., and Chory, J. (1995). CUE1: a mesophyll cell-specific positive regulator of light-controlled gene expression in Arabidopsis. Plant Cell 7, 1599-1610.

Li, N., Zhang, S., Zhao, Y., Li, B., and Zhang, J. (2011). Over-expression of AGPase genes enhances seed weight and starch content in transgenic maize. Planta 233, 241-250. doi: 10.1007/s00425-010-1296-5

Li-Beisson, Y., Shorrosh, B., Beisson, F., Andresson, M. X., Arondel, V., Bates, P. D., etal. (2013). Acyllipid metabolism. Arabidopsis Book 11:e0161. doi: 10.1199/tab.0161

Lohaus, G., Burba, M., and Heldt, H. W. (1994). Comparison of the contents of sucrose and amino acids in the leaves, phloem sap and taproots of high and low sugar-producing hybrids of sugar beet (Beta vulgaris L.). J. Exp. Bot. 45, 1097-1101. doi: 10.1093/jxb/45.8.1097

Lohaus, G., Winter, H., Riens, B., and Heldt, H. W. (1995). Further studies on the phloem loading process in leaves of barley and spinach. The comparison of metabolite concentrations in the apoplastic compartment with those in the cytosolic compartment and in sieve tubes. Bot. Acta 108, 270-275.

Long, S. P., Zhu, X.-G., Naidu, S. L., and Ort, D. R. (2006). Can improvement in photosynthesis increase crop yields? Plant Cell Environ. 29, 315-330. doi: 10.1111/j.13653040.2005.01493.x

Makino, A. (2011). Photosynthesis, grain yield, and nitrogen utilization in rice and wheat. Plant Physiol. 155, 125-129. doi: 10.1104/ pp. 110.165076

Manning, K., Davies, C., Bowen, H. C., and White, P. J. (2001) Functional characterization of two ripening-related sucrose transporters from grape berries. Ann. Bot 87, 125-129. doi: 10.1006/anbo. 2000.1316

Martinoia, E., Massonneau, A., and Frangne, N. (2000). Transport processes of solutes across the vacuolar membrane of higher plants. Plant Cell Physiol. 41, 1175-1186. doi: $10.1093 / \mathrm{pcp} / \mathrm{pcd} 059$

McCormick, A. J., Cramer, M. D. and Watt, D. A. (2006). Sink strength regulates photosynthesis in sugarcane. New Phytol. 171, 759770. doi: $10.1111 /$ j.1469-8137.2006 01785.x

McCormick, A. J., Cramer, M. D. and Watt, D. A. (2008). Changes in photosynthetic rates and gene expression of leaves during a sourcesink perturbation in sugarcane. Ann. Bot. 101, 89-102. doi: 10.1093/aob/ $\mathrm{mcm} 258$

McCouch, S. (2004). Diversifying selection in plant breeding. PLoS Biol. 2:e347. doi: 10.1371/journal.pbio.0020347

McCurdy, D. W., Dibley, S., Cahyanegara, R., Martin, A., and Patrick, J. W. (2010). Functional characterization and RNAi-mediated suppression reveals roles for hexose transporters in sugar accumulation by tomato fruit. Mol. Plant 3, 1049-1063. doi: $10.1093 / \mathrm{mp} / \mathrm{ssq} 050$

Melkus, G., Rolletschek, H., Radchuk, R., Fuchs, J., Rutten, T., Wobus, U., et al. (2009). The metabolic role of the legume endosperm: a noninvasive imaging study. Plant Physiol. 151, 1139-1154. doi: 10.1104/pp.109. 143974
Meyer, S., Lauterbach, C., Niedermeier, M., Barth, I., Sjolund, R. D., and Sauer, N. (2004). Wounding enhances expression of AtSUC3, a sucrose transporter from Arabidopsis sieve elements and sink tissues. Plant Physiol. 134, 684-693. doi: 10.1104/pp.103.033399

Meyer, S., Melzer, M., Truernit, E., Hümmer, C., Besenbeck, R., Stadler, R., etal. (2000). AtSUC3, a gene encoding a new Arabidopsis sucrose transporter, is expressed in cells adjacent to the vascular tissue and in a carpel cell layer. Plant J. 24, 869-882.

Minchin, P. E. H., Ryan, K. G., and Thorpe, M. R. (1984). Further evidence of apoplastic unloading into the stem of bean: identification of the phloem buffering pool. J. Exp. Bot. 35, 1744-1753. doi: 10.1093/jxb/35.12.1744

Minchin, P. E. H., and Thorpe, M. R. (1987). Measurement of unloading and reloading of photo-assimilate within the stem of bean. J. Exp. Bot. 38, 211-220. doi: 10.1093/ $\mathrm{jxb} / 38.2 .211$

Miranda, M., Borisjuk, L., Tewes, A., Heim, U., Sauer, N., Wobus, U., et al. (2001). Amino acid permeases in developing seeds of Vicia faba L.: expression precedes storage protein synthesis and is regulated by amino acid supply. Plant J. 28, 6172. doi: 10.1046/j.1365-313X.2001. 01129.x

Möhlmann, T., Tjaden, J., Henrichs, G., Quick, W. P., Häusler, R., and Neuhaus, H. E. (1997). ADP-glucose drives starch synthesis in isolated maize endosperm amyloplasts: characterization of starch synthesis and transport properties across the amyloplast envelope. Biochem. J. 324, 503-509.

Münch, E. (1930). Die Stoffbewegungen in der Pflanze. Jena: Verlag Gustav Fischer, 234.

Nguyen-Quoc, B., and Foyer, C. H. (2001). A role for 'futile cycles' involving invertase and sucrose synthase in sucrose metabolism of tomato fruit. J. Exp. Bot. 52, 881-889. doi: 10.1093/jexbot/52.358.881

Niittylä, T., Messerli, G., Trevisan, M., Chen, J., Smith, A. M., and Zeeman, S. C. (2004). A previously unknown maltose transporter essential for starch degradation in leaves. Science 303, 87-89. doi: 10.1126/science.1091811

Patrick, J. W., and Offler, C. E. (2001). Compartmentation of transport and transfer events in developing seeds. J. Exp. Bot. 52, 551-564. doi: $10.1093 /$ jexbot/52.356.551 
Paul, M. J., and Foyer, C. H. (2001). Sink regulation of photosynthesis. J. Exp. Bot. 52, 1383-1400. doi: 10.1093/jexbot/52.360.1383

Paul, M. J., and Pellny, T. K. (2003). Carbon metabolite feedback regulation of leaf photosynthesis and development. J. Exp. Bot. 54, 539-547. doi: 10.1093/jxb/erg052

Payyavula, R. S., Tay, K. H. C., Tsai, C.-J., and Harding, S. A. (2011). The sucrose transporter family in Populus: the importance of a tonoplast PtaSUT4 to biomass and carbon partitioning. Plant J. 65, 757770. doi: 10.1111/j.1365-313X.2010. 04463.x

Periappuram, C., Steinhauer, L., Barton, D. L., Taylor, D. C., Chatson, B., and Zou, J. (2000). The plastidic phosphoglucomutase from Arabidopsis. A reversible enzyme reaction with an important role in metabolic control. Plant Physiol. 122, 1193-1199. doi: 10.1104/pp.122.4.1193

Petreikov, M., Yeselson, L., Shen, S., Levin, I., Schaffer, A. A., Efrati, A., et al. (2009). Carbohydrate balance and accumulation during development of near-isogenic tomato lines differing in the AGPaseL1 allele. J. Am. Soc. Hortic. Sci. 134, 134-140.

Pommerrenig, B., Popko, J., Heilmann, M., Schulmeister, S., Dietel, K., Schmitt, B., et al. (2013). SUCROSE TRANSPORTER 5 supplies Arabidopsis embryos with biotin and affects triacylglycerol accumulation. Plant J. 73, 392-404. doi: 10.1111/tpj.12037

Poschet, G., Hannich, B., Raab, S. Jungkunz, I., Klemens, P. A. W., Krüger, S., et al. (2011). A novel Arabidopsis vacuolar glucose exporter is involved in cellular sugar homeostasis and affects the composition of seed storage compounds. Plant Physiol. 157, 1664-1676.

Rae, A. L., Jackson, M. A., Nguyen, C. H., and Bonnett, G. D. (2009). Functional specialization of vacuoles in sugarcane leaf and stem. Tropical Plant Biol. 2, 13-22. doi: 10.1007/s12042-008-9019-9

Rae, A. L., Perroux, J. M., and Grof, C. P. L. (2005). Sucrose partitioning between vascular bundles and storage parenchyma in the sugarcane stem: a potential role for the ShSUT1 sucrose transporter. Planta 220, 817-825. doi: 10.1007/s00425-0041399-y

Ramaiah, M., Jain, A., Baldwin, J. C., Karthikeyan, A. S., and Raghothama, K. G. (2011). Characterization of the phosphate starvationinduced glycerol-3-phosphate permease gene family in Arabidopsis. Plant Physiol. 157, 279-291. doi: 10.1104/pp.111.178541

Rawsthorne, S. (2002). Carbon flux and fatty acid synthesis in plants. Prog. Lipid Res. 41, 182-196. doi: 10.1016/S0163-7827(01)00023-6

Reidel, E. J., Turgeon, R., and Cheng, L. (2008). A maltose transporter from apple is expressed in source and sink tissues and complements the Arabidopsis maltose exportdefective mutant. Plant Cell Physiol. 49, 1607-1613. doi: 10.1093/pcp/ pcn 134

Reinders, A., Sivitz, A. B., Starker, C. G., Gantt, J. S., and Ward, J. M. (2008). Functional analysis of LjSUT4, a vacuolar sucrose transporter from Lotus japonicus. Plant Mol. Biol. 68, 289-299. doi: 10.1007/s11103-0089370-0

Reinders, A., Sivitz, A. B., and Ward, J. M. (2012). Evolution of plant sucrose uptake transporters. Front. Plant Sci. 3:22. doi: 10.3389/fpls. 2012.00022

Reiser, J., Linka, N., Lemke, L., Jeblick, W., and Neuhaus, $H$. E. (2004). Molecular physiological analysis of the two plastidic ATP/ADP transporters from Arabidopsis. Plant Physiol. 136, 3524-3536. doi: 10.1104/pp.104. 049502

Renné, P., Dressen, U., Hebbeker, U., Hille, D., Flügge, U.-I., Westhoff, P. et al. (2003). The Arabidopsis mutant $\mathrm{dct}$ is deficient in the plastidic glutamate/malate translocator DiT2. Plant J. 35, 316-331.

Rennie, E. A., and Turgeon, R. (2009). A comprehensive picture of phloem loading strategies. Proc. Natl. Acad. Sci. U.S.A. 106, 14162-14167. doi: 10.1073/pnas.0902279106

Riesmeier, J. W., Flügge, U.-I., Schulz, B., Heineke, D., Heldt, H.-W., Willmitzer, L., et al. (1993a). Antisense repression of the chloroplast triose phosphate translocator affects carbon partitioning in transgenic potato plants. Proc. Natl. Acad. Sci. U.S.A. 90, 6160-6164.

Riesmeier, J. W., Hirner, B., and Frommer, W. B. (1993b). Potato sucrose transporter expression in minor veins indicates a role in phloem loading. Plant Cell 5, 1591-1598.

Riesmeier, J. W., Willmitzer, L., and Frommer, W. B. (1992). Isolation and characterization of a sucrose carrier cDNA from spinach by functional expression in yeast. EMBO J. 11, 4705-4713.

Riesmeier, J. W., Willmitzer, L., and Frommer, W. B. (1994). Evidence for an essential role of the sucrose transporter in phloem loading and assimilate partitioning. EMBO J. 13, $1-7$.

Robinson, N. L., Hewitt, J. D. and Bennett, A. B. (1988). Sink metabolism in tomato fruit. I. Developmental changes in carbohydrate metabolizing enzymes. Plant Physiol. 87, 727-730. doi: 10.1104/pp. 87.3.727

Rodríguez-Falcón, M., Bou, J., and Prat, S. (2006). Seasonal control of tuberization in potato: conserved elements with the flowering response. Annu. Rev. Plant Biol. 57, 151-180.

Rolletschek, H., Hosein, F., Miranda, M., Heim, U., Götz, K.-P., Schlereth, A., et al. (2005). Ectopic expression of an amino acid transporter (VfAAP1) in seeds of Vicia narbonensis and pea increases storage proteins. Plant Physiol. 137, 1236-1249.

Rolletschek, H., Nguyen, T. H., Häusler R. E., Rutten, T., Göbel, C., Feussner, I., et al. (2007). Antisense inhibition of the plastidial glucose-6phosphate/phosphate translocator in Vicia seeds shifts cellular differentiation and promotes protein storage. Plant J. 51, 468-484.

Rosche, E., Blackmore, D., Tegeder, M., Richardson, T., Schroeder, H., Higgins, T. J. V., et al. (2002) Seed-specific overexpression of a potato sucrose transporter increases sucrose uptake and growth rates of developing pea cotyledons. Plant J. 31, 165-175. doi: 10.1046/j.1365 313X.2002.01282.x

Ruan, Y.-L., and Patrick, J. W. (1995). The cellular pathway of postphloem sugar transport in developing tomato fruit. Planta 196, 434-444. doi: 10.1007/BF00203641

Ruan, Y.-L., Patrick, J. W., and Brady, C. (1997). Protoplast hexose carrier activity is a determinate of genotypic difference in hexose storage in tomato fruit. Plant Cell Environ. 20, 341349. doi: 10.1046/j.1365-3040.1997. d01-73.x

Saftner, R. A., Daie, J., and Wyse, R. E. (1983). Sucrose uptake and compartmentation in sugar beet taproot tissue. Plant Physiol. 72, 1-6. doi: 10.1104/pp.72.1.1

Sauer, N. (2007). Molecular physiology of higher plant sucrose transporters. FEBS Lett. 581, 23092317. doi: 10.1016/j.febslet.2007. 03.048

Sauer, N., and Stolz, J. (1994). SUC1 and SUC2: two sucrose transporters from Arabidopsis thaliana; expression and characterization in baker's yeast and identification of the histidine-tagged protein. Plant
J. 6, 67-77. doi: 10.1046/j.1365 313X.1994.6010067.x

Schaffer, A. A., and Petreikov, M. (1997). Sucrose-to-starch metabolism in tomato fruit undergoing transient starch accumulation. Plant Physiol. 113, 739-746.

Schattat, M., Barton, K., Baudisch, B., Klösgen, R. B., and Mathur, J. (2011). Plastid stromule branching coincides with contiguous endoplasmic reticulum dynamics. Plant Physiol. 155, 1667-1677. doi: 10.1104/pp.110. 170480

Schmitt, B., Stadler, R., and Sauer, N. (2008). Immunolocalization of solanaceous SUT1 proteins in companion cells and xylem parenchyma: new perspectives for phloem loading and transport. Plant Physiol. 148, 187-199. doi: 10.1104/ pp. 108.120410

Schmitz, J., Schöttler, M. A., Krüger, S., Geimer, S., Schneider, A., Kleine, T., et al. (2012). Defects in leaf carbohydrate metabolism compromise acclimation to high light and lead to a high chlorophyll fluorescence phenotype in Arabidopsis thaliana. BMC Plant Biol. 12:8. doi:10.1186/14712229-12-8

Schneider, A., Häusler, R. E., Kolukisaoglu, Ü., Kunze, R., van der Graaff, E., Schwacke, R., et al. (2002). An Arabidopsis thaliana knock-out of the chloroplast triose phosphate/phosphate transloctor is severely compromised only when starch synthesis, but not starch mobilization is abolished. Plant J. 32, 685-699.

Schneider, S., Hulpke, S., Schulz, A., Yaron, I., Höll, J., Imlau, A., et al. (2012). Vacuoles release sucrose via tonoplast-localised SUC4-type transporters. Plant Biol. 14, 325336. doi: 10.1111/j.1438-8677.2011. 00506.x

Schneidereit, A., Scholz-Starke, J., and Büttner, M. (2003). Functional characterization and expression analyses of the glucose-specific AtSTP9 monosaccharide transporter in pollen of Arabidopsis. Plant Physiol. 133, 182-190.

Schulz, A., Beyhl, D., Marten, I., Wormit, A., Neuhaus, E., Poschet, G., et al. (2011). Proton-driven sucrose symport and antiport are provided by the vacuolar transporters SUC4 and TMT1/2. Plant J. 68, 129136. doi: 10.1111/j.1365-313X.2011. 04672.x

Shannon, J. C., Pein, F. M., Cao, H. P., and Liu, K. C. (1998). Brittle-1, an adenylate translocator, facilitates transfer of extraplastidial synthesized ADP-glucose into 
amyloplasts of maize endosperm. Plant Physiol. 117, 1235-1252. doi: 10.1104/pp.117.4.1235

Shockey, J. M., Fulda, M. S., and Browse, J. A. (2002). Arabidopsis contains nine long-chain acyl-coenzyme A synthetase genes that participate in fatty acid and glycerolipid metabolism. Plant Physiol. 129, 1710-1722. doi: 10.1104/pp.003269

Sivitz, A. B., Reinders, A., Johnson, M. E., Krentz, A. D., Grof, C. P. L., Perroux, J. M., et al. (2007). Arabidopsis sucrose transporter SUC9. High-affinity transport activity, intragenic control of expression, and early flowering mutant phenotype. Plant Physiol. 143, 188-198. doi: 10.1104/pp.106. 089003

Slewinski, T. L., Garg, A., Johal, G. S., and Braun, D. M. (2010). Maize SUT1 functions in phloem loading. Plant Signal. Behav. 5, 687-690. doi: 10.4161/psb.5.6.11575

Slewinski, T. L., Meeley, R., and Braun, D. M. (2009). Sucrose transporterl functions in phloem loading in maize leaves. J. Exp. Bot. 60, 881-892. doi: 10.1093/jxb/ern335

Smidansky, E. D., Clancy, M. Meyer, F. D., Lanning, S. P., Blake, N. K., Talbert, L. E., et al. (2002). Enhanced ADP-glucose pyrophosphorylase activity in wheat endosperm increases seed yield. Proc. Natl. Acad. Sci. U.S.A. 99, 1724-1729. doi: $10.1073 /$ pnas.022635299

Somerville, S. C., and Ogren, W. L. (1983). An Arabidopsis thaliana mutant defective in chloroplast dicarboxylate transport. Proc. Natl. Acad. Sci. U.S.A. 80, 1290-1294. doi: $10.1073 /$ pnas.80.5.1290

Somerville, S. C., and Somerville, C. R. (1985). A mutant of Arabidopsis deficient in chloroplast dicarboxylate transport is missing an envelope protein. Plant Sci. Lett. 37, 217-220. doi: 10.1016/0304-4211 (85)90007-0

Sonnewald, U. (2011). SWEETS the missing sugar efflux carriers. Front. Plant Sci. 2:7. doi: 10.3389/fpls.2011.00007

Sonnewald, U., Brauer, M., von Schaewen, A., Stitt, M., and Willmitzer, L. (1991). Transgenic tobacco plants expressing yeastderived invertase in either the cytosol, vacuole or apoplast: a powerful tool for studying sucrose metabolism and sink/source interactions. Plant J. 1, 95-106. doi: 10.1111/j.1365313X.1991.00095.x

Sonnewald, U., Hajirezaei, M.-R., Kossmann, J., Heyer, A., Trethewey, R. N., and Willmitzer, L. (1997).
Increased potato tuber size resulting from apoplastic expression of a yeast invertase. Nat. Biotechnol. 15, 794-797. doi: 10.1038/ nbt0897-794

Srivastava, A. C., Ganesan, S., Ismail, I. O., and Ayre, B. G. (2008). Functional characterization of the Arabidopsis AtSUC2 sucrose/H+ symporter by tissue-specific complementation reveals an essential role in phloem loading but not in longdistance transport. Plant Physiol. 148, 200-211. doi: 10.1104/pp.108. 124776

Stadler, R., Brandner, J., Schulz, A., Gahrtz, M., and Sauer, N. (1995). Phloem loading by the PmSUC2 sucrose carrier from Plantago major occurs into companion cells. Plant Cell 7, 1545-1554. doi: 10.1105/tpc.7.10.1545

Stadler, R., and Sauer, N. (1996). The Arabidopsis thaliana AtSUC2 gene is specifically expressed in companion cells. Bot. Acta 109, 299-306. doi: 10.1104/pp.008037

Stadler, R., Wright, K. M., Lauterbach, C., Amon, G., Gahrtz, M., Feuerstein, A., et al. (2005a). Expression of GFP-fusions in Arabidopsis companion cells reveals non-specific protein trafficking into sieve elements and identifies a novel post-phloem domain in roots. Plant J. 41, 319331. doi: 10.1111/j.1365-313X.2004. 02298.x

Stadler, R., Lauterbach, C., and Sauer, N. (2005b). Cell-to-cell movement of green fluorescent protein reveals post-phloem transport in the outer integument and identifies symplastic domains in Arabidopsis seeds and embryos. Plant Physiol. 139, 701-712. doi: 10.1104/pp.105.065607

Stettler, M., Eicke, S., Mettler, T., Messerli, G., Hörtensteiner, S., and Zeeman, S. (2009). Blocking the metabolism of starch breakdown products in Arabidopsis leaves triggers chloroplast degradation. Mol. Plant 2, 1233-1246. doi: $10.1093 / \mathrm{mp} / \mathrm{ssp} 093$

Stitt, M. (1991). Rising CO2 levels and their potential significance for carbon flow in photosynthetic cells. Plant Cell. Environ. 14, 741762. doi: 10.1111/j.1365-3040.1991. tb01440.x

Streatfield, S. J., Weber, A., Kinsman, E. A., Häusler, R. E., Li, J., PostBeittenmiller, D., et al. (1999). The phosphoenolpyruvate/phosphate translocator is required for phenolic metabolism, palisade cell development, and plastid-dependent nuclear gene expression. Plant Cell 11, 1609-1621.
Sullivan, T. D., and Kaneko, Y. (1995). The maize brittle-1 gene encodes amyloplast membrane polypeptides. Planta 196, 477-484. doi: 10.1007/BF00203647

Tegeder, M., Wang, X.-D., Frommer, W. B., Offler, C. E., and Patrick, J. W. (1999). Sucrose transport into developing seed of Pisum sativum L. Plant J. 18, 151-161. doi: 10.1046/j.1365313X.1999.00439.x

Thorbjörnsen, T., Villand, P., Denyer, K., Olsen, O.-A., and Smith, A. M. (1996). Distinct isoforms of ADPglucose pyrophosphorylase occur inside and outside the amyloplasts in barley endosperm. Plant J. 10, 243-250. doi: 10.1046/j.1365313X.1996.10020243.x

Tjaden, J., Möhlmann, T., Kampfenkel, K., Henrichs, G., and Neuhaus, H. E. (1998). Altered plastidic ATP/ADP-translocator activity influences potato (Solanum tuberosum L.) tuber morphology, yield and composition of tuber starch. Plant J. 16, 531-540. doi: 10.1046/j.1365313x.1998.00317.x

Trentmann, O., Jung, B., Neuhaus, H. E., and Haferkamp, I. (2008) Non-mitochondrial ATP/ADP transporters accept phosphate as third substrate. J. Biol. Chem. 283, 36486-36493. doi: 10.1074/ jbc.M806903200

Truernit, E., and Sauer, N. (1995). The promoter of the Arabidopsis thaliana sucrose- $\mathrm{H}+$ symporter gene directs expression of $\beta$-glucuronidase to the phloem: evidence for phloem loading and unloading by SUC2. Planta 196, 564-570. doi: 10.1007/ BF00203657

Turgeon, R. (1989). The sink-source transition in leaves. Annu. Rev. Plant Physiol. Plant Mol. Biol. 40, 119-138. doi: 10.1146/annurev.pp. 40.060189.001003

Uys, L., Botha, F. C., Hofmeyr, J.-H. S., and Rohwer, J. M. (2007). Kinetic model of sucrose accumulation in maturing sugarcane culm tissue. Phy tochemistry 68, 2375-2392. doi: 10.1016/j.phytochem.2007.04.023

van Dongen, J. T., Ammerlaan, A. M. H., Wouterlood, M., van Aelst, A. C. and Borstlap, A. C. (2003). Structure of the developing pea seed coat and the post-phloem transport pathway of nutrients. Ann. Bot. 91, 729-737. doi: $10.1093 / \mathrm{aob} / \mathrm{mcg} 066$

Vigeolas, H., Möhlmann, T., Martini, N., Neuhaus, H. E., and Geigenberger, P. (2004). Embryo-specific reduction of ADP-Glc pyrophosphorylase leads to an inhibition of starch synthesis and a delay in oil accumulation in developing seeds of oilseed rape. Plant Physiol. 136, 2676-2686. doi: 10.1104/pp.104.046854

Viola, R., Roberts, A. G., Haupt, S., Gazzani, S., Hancock, R. D., Marmiroli, N., etal. (2001). Tuberization in potato involves a switch from apoplastic to symplastic phloem unloading. Plant Cell 13, 385-398.

Vitale, A., and Ceriotti, A. (2004). Protein quality control mechanisms and protein storage in the endoplasmic reticulum. A conflict of interests? Plant Physiol. 136, 3420-3426. doi: 10.1104/pp.104.050351

Voll, L., Häusler, R. E., Hecker, R., Weber, A., Weissenböck, G., Fiene, G., et al. (2003). The phenotype of the Arabidopsis cuel mutant is not simply caused by a general restriction of the shikimate pathway. Plant J. 36, 301-317.

von Schaewen, A., Stitt, M., Schmidt, R., Sonnewald, U., and Willmitzer, L. (1990). Expression of a yeast-derived invertase in the cell wall of tobacco and Arabidopsis plants leads to accumulation of carbohydrate and inhibition of photosynthesis and strongly influences growth and phenotype of transgenic tobacco plants. EMBO J. 9, 3033-3044.

Walters, R. G., Ibrahim, D. G., Horton, P., and Kruger, N. J. (2004). A mutant of Arabidopsis lacking the triose-phosphate/phosphate translocator reveals metabolic regulation of starch breakdown in the light. Plant Physiol. 135, 891-906. doi: 10.1104/pp.104.040469

Wang, Z., Chen, X., Wang, J., Liu, T., Liu, Y., Zhao, L., et al. (2007). Increasing maize seed weight by enhancing the cytoplasmic ADP-glucose pyrophosphorylase activity in transgenic maize plants. Plant Cell Tissue Organ Cult. 88, 83-92. doi: 10.1007/s11240-0069173-4

Weber, A., Servaites, J. C., Geiger, D. R., Kofler, H., Hille, D., Gröner, F., et al. (2000). Identification, purification, and molecular cloning of a putative plastidic glucose translocator. Plant Cell 12, 787-802.

Weber, H., Borisjuk, L., Heim, U., Sauer, N., and Wobus, U. (1997). A role for sugar transporters during seed development: molecular characterization of a hexose and a sucrose carrier in fava bean seeds. Plant Cell 9, 895-908. doi: 10.1105/tpc.9. 6.895

Weise, A., Barker, L., Kühn, C., Lalonde, S., Buschmann, H., Frommer, W. B., etal. (2000). A new subfamily of sucrose transporters, SUT4, with low affinity/high capacity localized in enucleate sieve elements of 
plants. Plant Cell 12, 1345-1355. doi: 10.1105/tpc.12.8.1345

Weise, S. E., Weber, A. P. M., and Sharkey, T. D. (2004). Maltose is the major form of carbon exported from the chloroplast at night. Planta 218, 474-482. doi: 10.1007/s00425-0031128-y

Werner, D., Gerlitz, N., and Stadler, R. (2011). A dual switch in phloem unloading during ovule development in Arabidopsis. Protoplasma 248, 225-235. doi: 10.1007/s00709-0100223-8

Weschke, W., Panitz, R., Sauer, N., Wang, Q., Neubohn, B., Weber, H., et al. (2000). Sucrose transport into barley seeds: molecular characterization of two transporters and implications for seed development and starch accumulation. Plant J. 21, 455-467. doi: 10.1046/j.1365313x.2000.00695.x

Whittaker, A., and Botha, F. C. (1997). Carbon partitioning during sucrose accumulation in sugarcane intermodal tissue. Plant Physiol. 115, 1651-1659. doi: 10.1104/ pp.115.4.1651

Wingenter, K., Schulz, A., Wormit, A., Wic, S., Trentmann, O., Hoermiller, I. I., et al. (2010). Increased activity of the vacuolar monosaccharide transporter TMT1 alters cellular sugar partitioning, sugar signaling, and seed yield in Arabidopsis. Plant Physiol. 154, 665-677. doi: 10.1104/pp.110.162040

Wingenter, K., Trentmann, O., Winschuh, I., Hörmiller, I. I., Heyer,
A. G., Reinders, J., etal. (2011). A member of the mitogen-activated protein 3-kinase family is involved in the regulation of plant vacuolar glucose uptake. Plant J. 68, 890900. doi: 10.1111/j.1365-313X.2011 04739. $x$

Winter, D., Vinegar, B., Nahal, H., Ammar, R., Wilson, G. V., and Provart, N. J. (2007). An 'electronic fluorescent pictograph' browser for exploring and analyzing large-scale biological data sets. PLOS ONE 2:e718. doi: 10.1371/journal.pone.0000718

Wippel, K., and Sauer, N. (2012). Arabidopsis SUC1 loads the phloem in suc2 mutants when expressed from the SUC2 promoter. J. Exp. Bot. 63, 669-679. doi: 10.1093/jxb/ err255

Wormit, A., Trentmann, O., Feifer, I., Lohr, C., Tjaden, J., Meyer, S., et al. (2006). Molecular identification and physiological characterization of a novel monosaccharide transporter from Arabidopsis involved in vacuolar sugar transport. Plant Cell 18, 3476-3490. doi: 10.1105/tpc.106. 047290

Wyse, R. (1979). Sucrose uptake by sugar beet tap root tissue. Plant Physiol. 64, 837-841. doi: 10.1104/pp.64.5.837

Yamada, K., Osakabe, Y., Mizoi, J., Nakashima, K., Fujita, Y., Shinozaki, K., et al. (2010). Functional analysis of an Arabidopsis thaliana abioticstress-inducible facilitated diffusion transporter for monosaccharides. $J$.
Biol. Chem. 285, 1138-1146. doi 10.1074/jbc.M109.054288

Yu, T.-S., Kofler, H., Häusler, R. E., Hille, D., Flügge, U.-I., Zeeman, S. C., et al. (2001). The Arabidopsis sexl mutant is defective in the R1 protein, a general regulator of starch degradation in plants, and not in the chloroplast hexose transporter. Plant Cell 13, 1907-1918.

Zhang, L., Häusler, R. E., Greiten, C., Hajirezaei, M.-R., Haferkamp, I., Neuhaus, H. E., et al. (2008). Overriding the co-limiting import of carbon and energy into tuber amyloplasts increases the starch content and yield of transgenic potato plants. Plant Biotechnol. J. 6, 453 464. doi: $10.1111 /$ j.1467-7652.2008 00332. $\mathrm{x}$

Zhang, X.-Y., Wang, X.-L., Wang, X.F., Xia, G.-H., Pan, Q.-H., Fan, R.-C., etal. (2006). A shift of phloem unloading from symplasmic to apoplasmic pathway is involved in developmental onset of ripening in grape berry. Plant Physiol. 142, 220-232. doi: 10.1104/pp.106 081430

Zhou, Y., Chan, K., Wang, T. L., Hedley, C. L., Offler, C. E., and Patrick, J. W. (2009). Intracellular sucrose communicates metabolic demand to sucrose transporters in developing pea cotyledons. J. Exp. Bot. 60, 71-85. doi: 10.1093/jxb/ern254

Zhou, Y., Qu, H., Dibley, K. E., Offler, C. E., and Patrick, J. W. (2007). A suite of sucrose transporters expressed in coats of developing legume seeds includes novel $\mathrm{pH}$-independent facilitators. Plant J. 49, 750764. doi: 10.1111/j.1365-313X.2006. 03000.x

Zhu, Y. J., Komor, E., and Moore, P. H. (1997). Sucrose accumulation in the sugarcane stem is regulated by the difference between the activities of soluble acid invertase and sucrose phosphate synthase. Plant Physiol. $115,609-616$.

Conflict of Interest Statement: The authors declare that the research was conducted in the absence of any commercial or financial relationships that could be construed as a potential conflict of interest.

Received: 08 April 2013; accepted: 13 June 2013; published online: 02 July 2013.

Citation: Ludewig $F$ and Flügge U-I (2013) Role of metabolite transporters in source-sink carbon allocation. Front. Plant Sci. 4:231. doi: 10.3389/fpls.2013. 00231

This article was submitted to Frontiers in Plant Physiology, a specialty of Frontiers in Plant Science.

Copyright (c) 2013 Ludewig and Flügge. This is an open-access article distributed under the terms of the Creative Commons Attribution License, which permits use, distribution and reproduction in other forums, provided the original authors and source are credited and subject to any copyright notices concerning any thirdparty graphics etc. 